\title{
On the estimation of boundary layer heights: a machine learning approach
}

\author{
Raghavendra Krishnamurthy ${ }^{1}$, Rob K. Newsom ${ }^{1}$, Larry K. Berg ${ }^{1}$, Heng Xiao ${ }^{1}$, Po-Lun Ma ${ }^{1}$, and David D. Turner ${ }^{2}$ \\ ${ }^{1}$ Pacific Northwest National Laboratory, ASGC Division, Richland, 99354, USA \\ ${ }^{2}$ National Oceanic and Atmospheric Administration/Global Systems Laboratory, Boulder, 80305, USA
}

Correspondence: Raghavendra Krishnamurthy (raghu@pnnl.gov)

Received: 4 November 2020 - Discussion started: 17 December 2020

Revised: 31 March 2021 - Accepted: 27 April 2021 - Published: 15 June 2021

\begin{abstract}
The planetary boundary layer height $\left(z_{i}\right)$ is a key parameter used in atmospheric models for estimating the exchange of heat, momentum, and moisture between the surface and the free troposphere. Near-surface atmospheric and subsurface properties (such as soil temperature, relative humidity, etc.) are known to have an impact on $z_{i}$. Nevertheless, precise relationships between these surface properties and $z_{i}$ are less well known and not easily discernible from the multi-year dataset. Machine learning approaches, such as random forest $(\mathrm{RF})$, which use a multi-regression framework, help to decipher some of the physical processes linking surface-based characteristics to $z_{i}$. In this study, a 4year dataset from 2016 to 2019 at the Southern Great Plains site is used to develop and test a machine learning framework for estimating $z_{i}$. Parameters derived from Doppler lidars are used in combination with over 20 different surface meteorological measurements as inputs to a RF model. The model is trained using radiosonde-derived $z_{i}$ values spanning the period from 2016 through 2018 and then evaluated using data from 2019. Results from 2019 showed significantly better agreement with the radiosonde compared to estimates derived from a thresholding technique using Doppler lidars only. Noteworthy improvements in daytime $z_{i}$ estimates were observed using the RF model, with a $50 \%$ improvement in mean absolute error and an $R^{2}$ of greater than $85 \%$ compared to the Tucker method $z_{i}$. We also explore the effect of $z_{i}$ uncertainty on convective velocity scaling and present preliminary comparisons between the RF model and $z_{i}$ estimates derived from atmospheric models.
\end{abstract}

\section{Introduction}

Measuring the growth of the planetary boundary layer (PBL) height is crucial for understanding the turbulent transfer of air mass, which in turn strongly influences the winds, temperature, and moisture within the atmospheric boundary layer. During daytime, the air within the PBL is well mixed due to convection and results in weakening of turbulence at the top of the PBL (entrainment zone). One of the characteristics of the top of the PBL during clear-sky conditions is that the turbulence is near zero, while in cases with boundary layer clouds, significant up- and downdrafts can be observed at the top of the boundary layer (typically the cloud base height). Routine, continuous, long-term monitoring of the PBL height, $z_{i}$, is crucial for evaluating climate, weather, and air quality model skill in representing near-surface turbulent mixing, entrainment across the PBL top, the development of shallow cumulus, understanding effects of morning or evening transitions (Grant, 1997), and nocturnal convection initiation (Reif and Bluestein, 2017). Profiles of potential temperature, water vapour mixing ratio, and particulate concentration often exhibit strong gradients at or near the top of the PBL. Typically, estimates of $z_{i}$ are obtained from an analysis of temperature and humidity profiles obtained from radiosondes. Indeed, radiosondes continue to be the de facto standard due to their long operational history, fine vertical resolution, accuracy, and reliability. However, major limitations are the poor temporal resolution and large sampling error because radiosondes are typically only launched twice daily at operational centres around the world. The launch time periods are generally not optimal for looking at various 
boundary layer properties. As a result, the diurnal variation in $z_{i}$ is usually poorly represented in radiosonde data.

Modern remote sensing instruments can provide continuous estimates of the boundary layer dynamics. Spacebased remote sensing instruments, such as Moderate Resolution Imaging Spectroradiometer, Tropical Rainfall Measuring Mission data and Multiangle Imaging SpectroRadiometer have also shown the ability to estimate PBL height (Wood and Bretherton, 2004; Karlsson et al., 2010).

Ground-based lidar systems, such as the Raman lidars (Turner et al., 2014), ceilometer, micro-pulse lidar (Campbell et al., 2002), atmospheric emitted radiance interferometer (Knuteson et al., 2004; Sawyer and Li, 2013), Doppler lidar (Tucker et al., 2009; Berg et al., 2017; Bonin et al., 2018; Vakkari et al., 2015; Banakh et al., 2021), and high-spectralresolution lidar, have been commonly used to provide PBL height estimates (Quan et al., 2013; McNicholas and Turner, 2014). For elastic lidar systems such as the micro-pulse lidar, $z_{i}$ is estimated by locating the height where the rangecorrected signal-to-noise ratio (SNR) or attenuated backscatter profile experiences a strong decrease with height (Emeis et al., 2008). A similar approach is used to estimate $z_{i}$ from profiles of water vapour mixing ratio from Raman lidar (Summa et al., 2013) or differential absorption lidar systems (Hennemuth and Lammert, 2006); however, the peak in the water vapour variance has also been used as an estimate of $z_{i}$ (Turner et al., 2014).

Doppler lidars provide range-resolved measurements of radial velocity, attenuated backscatter, and SNR. When staring vertically, a ground-based Doppler lidar measures heightresolved profiles of vertical velocity in the lower atmosphere with a temporal resolution of $1 \mathrm{~s}$ or less. Profiles of the vertical velocity variance can then be computed by averaging over an appropriate time interval (typically 15 to $30 \mathrm{~min}$ ). The primary advantage of Doppler lidars is that they measure the turbulence directly and thus provide a more defensible measure of $z_{i}$. Other systems rely on gradients of aerosol loading or moisture that are used to infer $z_{i}$.

One method for estimating the convective boundary layer (CBL) depth using Doppler lidars is to find the height where the vertical velocity variance profile falls below some prescribed threshold, which in some cases can vary with time (Lenschow et al., 2000; Tucker et al., 2009; Lenschow et al., 2012; Berg et al., 2017). This method, which we refer to as the Tucker method, is simple to implement and provides a direct measure of $z_{i}$. However, the estimates are sensitive to the choice of variance threshold, which is somewhat arbitrary. Also, this method fails under stable nocturnal conditions due to weak turbulence and the fact that the lowest gate of the lidar is often above the depth of the nocturnal $z_{i}$. Horizontal velocity variance and dissipation rate profiles from a Doppler lidar can be used to estimate $z_{i}$ in nocturnal conditions (Vakkari et al., 2015; Banakh et al., 2021). Alternatively, one can estimate the PBL height based on wind shear and turbulence kinetic energy (TKE), but there has been lim- ited research on this topic (Brost and Wyngaard, 1978; Teixeira and Cheinet, 2004; LeMone et al., 2018).

Due to different measurement approaches between multiple remote sensing instruments, considerable uncertainties exist when comparing $z_{i}$ to standard radiosonde retrievals. PBL heights from different instruments provide expected trends during certain atmospheric conditions (mostly daytime convective time periods) but differ slightly due to measurement uncertainties and thresholds chosen associated with each instrument. Therefore, a framework independent of threshold techniques used in previous studies is warranted. Although this paper does not directly address a unified approach to estimate $z_{i}$, it is a step in that direction.

In view of these limitations, we investigate the potential of using a machine learning (ML) approach for continuous monitoring of $z_{i}$, with a focus on CBL. ML enables us to bring together various observations to arrive at a consensus answer. ML models, such as RF and neural networks, have been used for classifying various atmospheric phenomena (McGovern et al., 2017; Gagne et al., 2019; Vassalo et al., 2020) or retrieving atmospheric variables (e.g. Solheim et al., 1998; Cadeddu et al., 2009). The RF model is versatile, simple to implement, and robust. Training the RF model entails providing it with observations (i.e. features) that aid in predicting $z_{i}$. Examples of such observations include surface sensible and latent heat flux, soil temperature, soil moisture, surface potential temperature, surface humidity, etc. These features have all been shown to exhibit some degree of correlation with $z_{i}$ (Santanello et al., 2005; Zhang et al., 2013).

Here we use a RF model to predict $z_{i}$ using input features derived from vertically staring Doppler lidar data and various surface and sub-surface observations. We use a multiyear dataset from the U.S. Department of Energy (DOE)'s Southern Great Plains (SGP) site (Sisterson et al., 2016) for training and evaluating the RF model. Reference $z_{i}$ measurements from radiosondes are used in the RF training process (Sivaraman et al., 2013). Specifically, the RF model is trained using observations from 2016 through 2018, and its performance is evaluated using data from 2019.

In this paper, Sect. 2 describes the observations that are used in this study, and Sect. 3 describes the details of the RF model, including the training method, data conditioning, and performance. Results of the RF model's performance are presented in Sect. 4, and in Sect. 5 we examine how RF modelderived $z_{i}$ estimates affect the scaling of the vertical velocity variance profiles. PBL height estimates from Energy Exascale Earth System Model (E3SM) Atmosphere Model version 1 (EAMv1), large-eddy simulations (LESs), and observations are compared in Sect. 6. Finally, a summary and future work are provided in Sect. 7. 


\section{Data sources}

The U.S. DOE Atmospheric Radiation Measurement (ARM) User Facility operates the SGP site in north-central Oklahoma (Mather and Voyles, 2013; Sisterson et al., 2016). The site contains an extensive suite of instrumentation for monitoring the atmosphere and surface properties. Most of these instruments operate continuously, and the data are freely available from the ARM website (https://adc.arm.gov/ discovery, last access: 5 May 2020; McCord and Voyles, 2016). The SGP site contains several heavily instrumented subsites or "facilities" that are geographically dispersed over Oklahoma and Kansas (Mather and Voyles, 2013). For this study, we use observations from the central facility (C1), which also contains the largest number and most diverse suite of instruments in ARM. Figure 1 shows the layout of the SGP C1 site and the locations of instruments used in this study. Additionally, Table 1 lists the instruments, ARM data stream names, and specific measurements that were used. In ML, independent variables, or inputs, are often referred to as features. A model can have multiple features/inputs and for this project, the measurements from the observations will be referred to as features in the RF model.

The ARM User Facility has operated a Halo Photonics Stream Line XR (Pearson et al., 2009) at C1 since April 2011. The instrument provides height- and time-resolved measurements of radial velocity, attenuated backscatter, and SNR. The range resolution is set to $30 \mathrm{~m}$ and the temporal resolution is about $1 \mathrm{~s}$. The instrument is configured to stare vertically most of the time. Once every $15 \mathrm{~min}$, it executes a plan-position-indicator scan, from which profiles of the wind speed and direction are computed. The vertical staring data are used to compute profiles of noise-corrected vertical velocity variance using a $30 \mathrm{~min}$ averaging period. More details about the instrument are provided by Newsom and $\mathrm{Kr}$ ishnamurthy (2020). Details about the vertical velocity statistics value-added product (VAP) are provided by Newsom et al. (2019b), and details about the Doppler lidar wind VAP are given by Newsom et al. (2019a).

Doppler-lidar-derived features used in this study are listed in Table 1. The list includes raw height-resolved measurements of attenuated backscatter and range-corrected SNR, which are known to be directly correlated with $z_{i}$ (Cohn and Angevine, 2000; Brooks, 2003). Also listed are several derived quantities such as cloud base height, wind shear, turbulence eddy dissipation rate, and $z_{i}$ estimated using the Tucker method (Tucker et al., 2009). Typically, the nocturnal vertical velocity variance estimates are too small, and the threshold used in the Tucker method is not applicable. During certain rare nocturnal convection initiation events, larger vertical velocity variance estimates are observed and the same threshold $\left(0.04 \mathrm{~m}^{2} \mathrm{~s}^{-2}\right)$ is used to estimate nighttime values of $z_{i}$ from the lidar. For consistency in terminology being used here, we refer to all $z_{i}$ estimates from the lidar as the Tucker method (both nighttime and daytime).

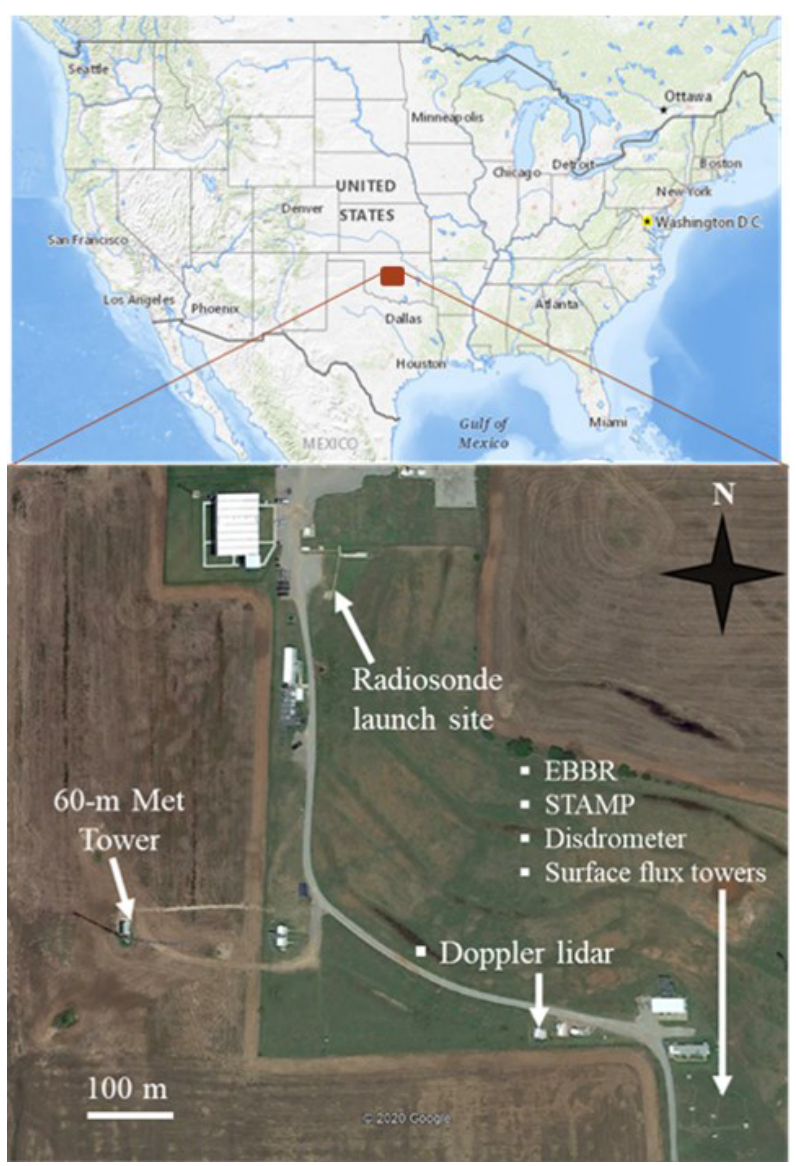

Figure 1. ARM SGP site C1 layout and instruments used in this study in Oklahoma, USA. Maps are extracted from (C) Google Earth and (C) Google Maps.

Because the range of the Doppler lidars at SGP C1 is often less than $1 \mathrm{~km}$ (see Appendix A), estimates of eddy dissipation rate (using $1 \mathrm{~Hz}$ vertical velocity stares; Champagne et al., 1977) above $800 \mathrm{~m}$ were affected by system noise. Thus, features such as the eddy dissipation rate, attenuated backscatter, and SNR from the Doppler lidar were limited to $800 \mathrm{~m}$ a.g.l. Reducing the height from 800 to $500 \mathrm{~m}$ a.g.l. did not impact the results. Moreover, RF models used in this study are only capable of ingesting one-dimensional time series data; therefore, two-dimensional Doppler lidar features were averaged over the vertical column (90 m (lowest range gate) to $800 \mathrm{~m}$ a.g.1.). Adding these features increased the overall variance explained by the RF model ( $82 \%$ of the total variance compared to $74 \%$ of the total variance without using lidar-derived parameters).

The ARM PBL VAP (sgppblhtsonde1mcfarlC1.c1) contains estimates of $z_{i}$ derived from radiosondes launched at $\mathrm{SGP} \mathrm{C} 1$. We note that radiosondes are typically launched four times daily from SGP C1, nominally at 0530, 1130, 17:30, and 23:30 UTC each day (local time $=$ UTC-6). The PBL VAP uses three different algorithms for estimating 
Table 1. Instruments, ARM data stream names, and measurements used in this study.

\begin{tabular}{|c|c|c|c|c|}
\hline Instrument & ARM data stream & Measurements or features & $\begin{array}{l}\text { Measurement height/ } \\
\text { range }\end{array}$ & References \\
\hline Radiosonde & sgppblhtsonde1mcfarlC1.c1 & PBL height estimates (m) & 100 to $5000 \mathrm{~m}$ a.g.l. & Sivaraman et al. (2013) \\
\hline \multirow[t]{8}{*}{$\begin{array}{l}\text { Surface eddy } \\
\text { correlation station }\end{array}$} & \multirow[t]{8}{*}{ sgp30co2flx $25 \mathrm{mC} 1 . b 1$} & Sensible heat flux $\left(\mathrm{W} \mathrm{m}^{-2}\right)$ & \multirow[t]{8}{*}{25 m a.g.l. } & \multirow[t]{8}{*}{$\begin{array}{l}\text { Cook (2018a) and Tang } \\
\text { et al. }(2019)\end{array}$} \\
\hline & & Latent heat flux $\left(\mathrm{W} \mathrm{m}^{-2}\right)$ & & \\
\hline & & $\begin{array}{l}\text { Vertical velocity variance } \\
\left(\mathrm{m}^{2} \mathrm{~s}^{-2}\right)\end{array}$ & & \\
\hline & & Friction velocity $\left(\mathrm{m} \mathrm{s}^{-1}\right)$ & & \\
\hline & & $\begin{array}{l}\text { Turbulence kinetic energy } \\
\left(\mathrm{m}^{2} \mathrm{~s}^{-2}\right)\end{array}$ & & \\
\hline & & Monin-Obukhov length (m) & & \\
\hline & & Wind speed $\left(\mathrm{m} \mathrm{s}^{-1}\right)$ & & \\
\hline & & $\begin{array}{l}\text { Wind direction (degrees from } \\
\text { north) }\end{array}$ & & \\
\hline \multirow{2}{*}{$\begin{array}{l}\text { Surface meteorological } \\
\text { station }\end{array}$} & \multirow[t]{2}{*}{ sgpmetE13.b1 } & Air temperature $(\mathrm{K})$ & \multirow[t]{2}{*}{$4 \mathrm{~m}$ a.g.l. } & \multirow[t]{2}{*}{ Ritsche and Prell (2011) } \\
\hline & & Relative humidity (\%) & & \\
\hline $\begin{array}{l}\text { Soil temperature and } \\
\text { moisture probes }\end{array}$ & $\begin{array}{l}\text { sgpstampE13.b1 or } \\
\text { sgpswatsE13.b1 }\end{array}$ & $\begin{array}{l}\text { Soil moisture }\left(\mathrm{m}^{3} \mathrm{~m}^{-3}\right) \\
\text { Soil temperature }\left({ }^{\circ} \mathrm{C}\right)\end{array}$ & $-5 \mathrm{~cm}$ below surface & Cook (2018b) \\
\hline $\begin{array}{l}\text { Surface energy balance } \\
\text { system/solar infrared } \\
\text { radiation station }\end{array}$ & $\begin{array}{l}\text { sgpqcrad1longE13.c1 and } \\
\text { sgpqcrad1longE13.c2 }\end{array}$ & $\begin{array}{l}\text { Best estimate of longwave, } \\
\text { shortwave, and normal radiation } \\
\left(\mathrm{W} \mathrm{m}^{-2}\right)\end{array}$ & $2 \mathrm{~m}$ a.g.l. & $\begin{array}{l}\text { Cook and Sullivan } \\
\text { (2019) }\end{array}$ \\
\hline \multirow[t]{3}{*}{ Doppler lidar } & sgpdlfptC1.b1 & $\begin{array}{l}\text { Range-corrected attenuated } \\
\text { backscatter variance }\left(\mathrm{m}^{-1} \mathrm{sr}^{-1}\right) \text {, } \\
\text { SNR variance }(\mathrm{dB}) \text {, and average } \\
\text { eddy dissipation rate }\left(\mathrm{m}^{2} \mathrm{~s}^{-3}\right)\end{array}$ & 90 to $800 \mathrm{~m}$ a.g.l. & $\begin{array}{l}\text { Champagne et al. (1977), } \\
\text { Newsom and } \\
\text { Krishnamurthy (2020) }\end{array}$ \\
\hline & sgpdlprofwstats4newsC1.c1 & $\begin{array}{l}\text { Cloud base height }(\mathrm{m}) \\
\text { CBL depth from Tucker } \\
\text { method }(\mathrm{m}) \\
\text { Year, month, and hour of day }\end{array}$ & 0 to $9000 \mathrm{~m}$ a.g.l. & $\begin{array}{l}\text { Newsom et al. (2019b), } \\
\text { Tucker et al. (2009) }\end{array}$ \\
\hline & sgpdlprofwinds4newsC1.c1 & $\begin{array}{l}\text { Wind shear exponent } \\
\left(\alpha=\log _{10}\left(\frac{U_{1}}{U_{2}}\right) / \log _{10}\left(\frac{Z_{1}}{Z_{2}}\right)\right) \text {, } \\
\text { where } U_{i} \text { and } Z_{i} \text { are wind speed } \\
\text { and height at altitude } i\end{array}$ & $\begin{array}{l}z_{1}=90 \mathrm{~m} \text { to } \\
z_{2}=300 \mathrm{~m} \text { a.g.l. (or } \\
\text { lower, depending on } \\
\text { data availability) }\end{array}$ & $\begin{array}{l}\text { Newsom et al. (2019a), } \\
\text { Wharton and Lundquist } \\
\text { (2012) }\end{array}$ \\
\hline
\end{tabular}

$z_{i}$. These include the Heffter (1980), two bulk Richardson thresholds methods, and Liu and Liang (2010). The Heffter (1980) method is a well-established and widely used algorithm (e.g. Marsik et al., 1995; Delle Monache et al., 2004) that determines $z_{i}$ from potential temperature gradients using criteria related to the strength of an inversion and the potential temperature difference across the inversion. The bulk Richardson number $\left(R i_{\mathrm{b}}\right)$ is a dimensionless number relating vertical stability to vertical shear. It represents the ratio of thermally produced turbulence to that generated by vertical shear. Methods using $R i_{\mathrm{b}}$ to estimate $z_{i}$ assume that there is no turbulence production at the top of the stable boundary layer, and therefore $R i_{\mathrm{b}}$ exceeds its critical value at the top of the boundary layer (Seibert et al., 2000). Several different critical thresholds of $R i_{\mathrm{b}}$ are provided in the literature based on resolution of sondes, location, etc. The ARM PBL VAP includes $z_{i}$ estimates based on two critical thresholds (0.25 and 0.5). Liu and Liang (2010) provide different thresholds for estimating convective and stable boundary layer depths using potential temperature profiles. The inversion strength thresholds used in the method varies for given stability regime and land type classification (land, ocean, or ice). We note that the various estimates can differ considerably. More details about the ARM PBL VAP are provided by Sivaraman et al. (2013). 


\section{Preliminary data analysis}

Boundary layer height estimation algorithms (Tucker et al., 2009; Berg et al., 2017; Bonin et al., 2018) purely using the Doppler lidars are limited by the range of the Doppler lidars at the ARM SGP facility, which may or may not reach the top of the boundary layer. The data availability of the ARM Doppler lidar SGP C1 systems is typically less than 1-2 km (Newsom and Krishnamurthy, 2020), and the data availability of the Doppler lidar vertical stares and velocity azimuth display scans for the study period are shown in Appendix A. The Tucker method $z_{i}$ is used for inter-comparison with the RF model in this study, primarily due to its ease in application to the multi-year dataset and known performance, including its established usage in studies using the ARM Doppler lidar and other locations and instruments (Träumner et al., 2011; Shukla et al., 2014; Schween et al., 2014; Berg et al., 2017; Lareau et al., 2018; Lareau, 2020). Vertical velocity variance profiles provided in the sgpdlprofwstats4newsC1.c1 VAP and a variance threshold of $0.04 \mathrm{~m}^{2} \mathrm{~s}^{-2}$ are used to determine $z_{i}$, following Tucker et al. (2009). The results are somewhat sensitive to the choice of threshold such that the $z_{i}$ estimates decrease as the threshold is increased (Berg et al., 2017).

Figure 2 shows a typical example of vertical velocity variance during the warm season at SGP. Also shown are estimates of $z_{i}$ from the Tucker method. We find that the Tucker method generally works well at tracking the height of the convective mixed layer during its initial development phase and can be made to match the radiosonde observations by changing the vertical velocity variance threshold (Schween et al., 2014). In that case, there is sufficient SNR for the lidar to see both the developing convection and the overlying residual layer. However, as the mixed layer continues to deepen, at some point the SNR becomes too small to enable reliable estimates of the vertical velocity variance. This problem is sometimes compounded by a slight reduction in sensitivity during the hottest portion of the day, which we suspect is the result of strong refractive turbulence in the surface layer. Although this effect has not been thoroughly analysed due to lack of refractive turbulence profiles and concurrent radiosonde data, there could be instances when the Doppler lidar is indeed measuring the top of the boundary layer. In any event, the loss of signal near the CBL top could result in $z_{i}$ estimates from the Tucker method being low biased.

For this study, radiosonde-derived $z_{i}$ estimates are used to calibrate the RF algorithm. Figure 3 shows comparisons between lidar-derived CBL (using the Tucker method) and simultaneous estimates from the ARM PBL VAP. These comparisons were performed using 1785 cases with radiosonde data and daytime clear (identified as periods when surface heat flux is positive from sunrise to sunset and cloud base height is zero) or shallow cumulus conditions (identified as cloud base height less than $5 \mathrm{~km}$ from Doppler lidar and cloud fraction less than 0.1) for the years 2016 through 2019. From these results, we found that the Liu and Liang (2010) technique resulted in the best overall agreement with the Tucker method $z_{i}$, in terms of the correlation coefficients $(r=0.75)$ and slope (0.70). Thus, $z_{i}$ estimates from the Liu-Liang technique in the ARM PBL VAP (pblhtsonde 1 mcfarl.c) are used as a reference to calibrate the RF model in this study. It should be noted that any of the above three model outputs can be used to calibrate the ML model, if needed, and the choice could vary with each site. For a different site, we would recommend conducting a similar correlation analysis as shown above with various radiosonde models and lidar data to determine the optimal model for RF calibration. It is important to note that during stable conditions, the determination of $z_{i}$ from radiosondes is very uncertain, as the turbulence can result from either buoyancy forcing or wind shear, and the radiosonde rapidly rises through the relatively thin stable boundary layer. At SGP C1, the nose of the lowlevel jet can also be used to define the height of the boundary layer (Sivaraman et al., 2013). Therefore, the focus of this study is to only demonstrate the ability of the RF model to replicate nighttime $z_{i}$ estimates compared to radiosondederived values. We hope this framework developed in this article can be adapted easily to future research in estimating the true stable boundary layer height from radiosondes or other reference sources. During stable conditions, the true $z_{i}$ can be below the lowest range gate of the Doppler lidar, and we expect such a technique would aid in representing true $z_{i}$ estimates with proper calibration.

\section{Machine learning}

In this study, an RF algorithm was used to predict PBL heights. RF regression (Breiman, 2001) is an ensemble method that is made up of a population of decision or decorrelated trees. Figure 4 provides a graphical illustration of the RF bootstrapping process. Bootstrap aggregation (bagging) is used so that each RF tree (a sample is shown in Appendix B) can randomly sample from an entire feature set, while only a subset of the total feature set is given to each individual tree. For example, if the entire feature set contains say $M$ different features, an individual RF tree can contain a fraction of those $M$ features. The premise behind RF is to improve the variance reduction of bagging by reducing the correlation between the trees without increasing the variance. The trees can be truncated to add further diversification. After construction, the population's individual predictions are averaged to give a final prediction of the target variable. Ideally, this process results in a diversified and decorrelated set of trees whose predictive errors cancel out, producing a more robust final prediction.

An advantage of RFs is their ability to determine the importance of all input features for the predictive process. This is done by calculating the mean decrease in impurity or the decrease in variance that is achieved during a given split in 


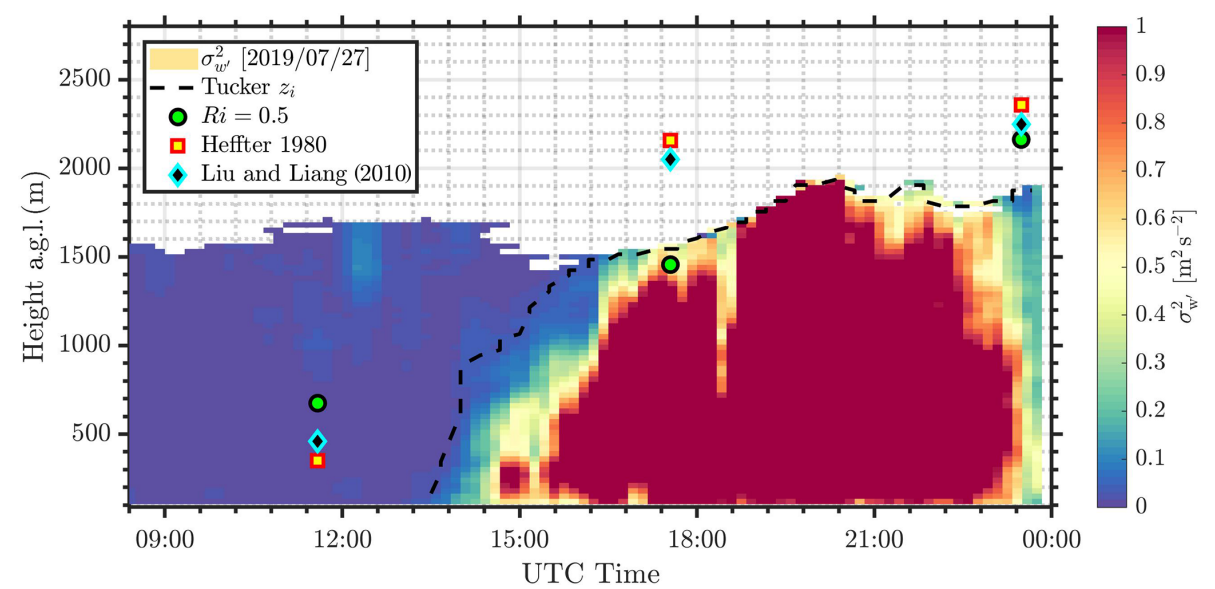

Figure 2. Typical CBL showing lidar variance (colours), Tucker $z_{i}$ (black line), and radiosonde $z_{i}$ (three methods; symbols). The horizontal axis shows the number of hours after 00:00 UTC on 27 July 2019.
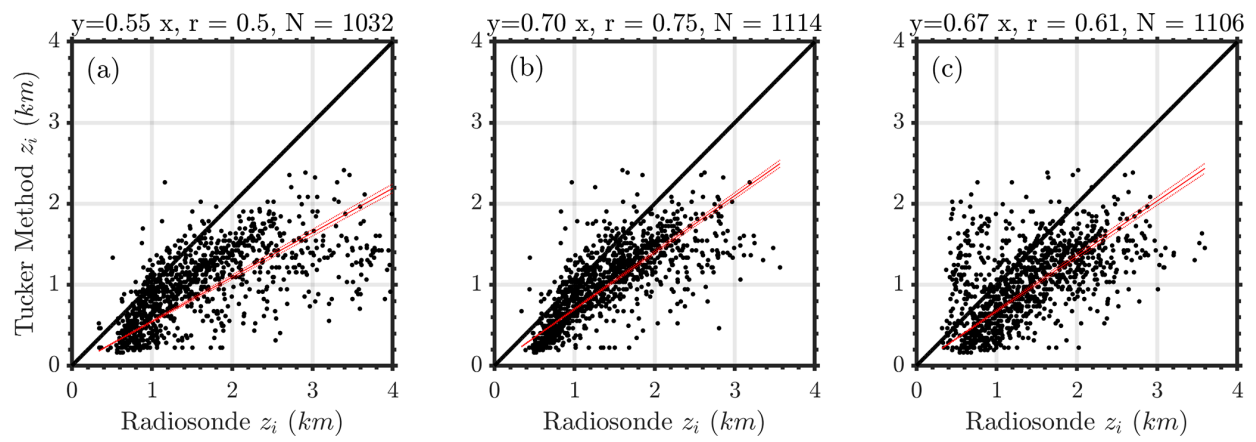

Figure 3. Comparisons between Tucker method and three different $z_{i}$ estimates from radiosondes. (a) Heffter (1980), (b) Liu and Liang (2010), and (c) bulk Richardson number method using a threshold of 0.5 . The red line is the best fit with the fit $y=m x$ shown above. $r$ is the correlation coefficient, and $N$ is the total number of radiosonde and Tucker method observations used in each scatter plot.

each decision tree. The decrease in impurity for each input feature can be averaged over the entire forest, providing an approximation of the feature's importance for the prediction (feature importance estimates sum to $100 \%$ to ease interpretability). A sample regression tree developed by real data used in this article is shown in Appendix B (Fig. B1). The statistics and ML toolbox in MATLAB contain all the functions needed to build the RF algorithm used in this study.

\subsection{Model hyperparameters}

In this study, a least-squares boosting regression (LSboost) ensemble RF model (Breiman, 2001) is built based on observational data listed in Table 1. At every iteration, the ensemble fits a new decision tree to minimize the mean-squared error between the observed response and the aggregated prediction of all decision trees developed previously. The MATLAB function fitrensemble is used to develop the RF model. The algorithm creates several regression trees using a subset of input features and radiosonde observations. The RF model creates a learning process to map the reference data to input features. Hyperparameters are used to control the learning process in the RF model. It is good practice to tune hyperparameters such as the maximum number of decision splits per tree (see Fig. 4), learn rate for shrinkage, and the number of iterations for reducing the generalization error (Breiman, 2001). In this article, hyperparameters for the RF model are chosen by performing a Bayesian optimization on the data, which minimizes the $k$-fold cross validation loss function for select hyperparameters (MATLAB function bayesopt). For this study, three hyperparameters were optimized: the number of tree splits, number of learning cycles or iterations, and learn rate for the model. Based on the optimization results, the number of iterations was set to 460 , number of tree splits to 11 , and learning rate to 0.25 for the current model.

Regularization techniques are used to prevent statistical overfitting in a predictive model (Hastie et al., 2009), by reducing the magnitude of the coefficients of the RF model for certain parameters that do not contribute to the target variable. In general, regularization algorithms can treat issues such as multicollinearity and redundant predictors and make the model more precise. The MATLAB function regularize 


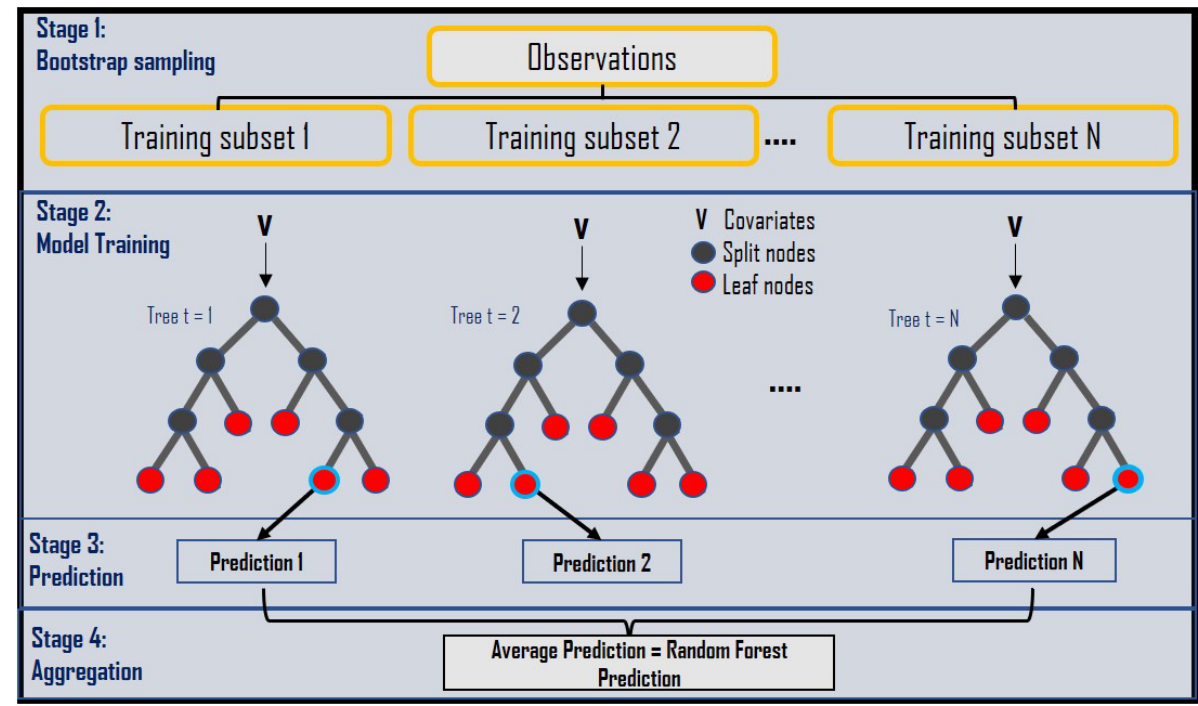

Figure 4. Graphical representation of a standard RF algorithm (adapted from online sources and Fig. A1).

is used for the regularization process, which is based on the Lasso regularization algorithm (Tibshirani, 1996). This regularization algorithm optimizes the number of trees and avoids data overfitting.

\subsection{Data preprocessing}

Surface and lidar data from 2016 to 2019 are used in this analysis. ARM VAPs provide processed and qualitycontrolled data from several atmospheric sensors. Each VAP provides quality control thresholds that are used to filter the data. For example, the lidar VAPs (DLWSTATS and DLWIND) provide quality control flags based on the system noise and SNR (Newsom and Krishnamurthy, 2020). For this analysis, thresholds specified in the VAPs are used to remove any erroneous data. Similarly, quality control flags for all variables mentioned in Table 1 above are used to filter bad data (Tang et al., 2019). Because the temporal resolution of the surface data are variable, measurements are interpolated or averaged to the lidar $15 \mathrm{~min}$ resolution time stamps. The frequency of radiosondes is generally $6 \mathrm{~h}$ at SGP but can be in intervals of $3 \mathrm{~h}$ during select field campaigns (Mather et al., 2018). For training purposes, surface and lidar data to the nearest radiosonde observations within $15 \mathrm{~min}$ are chosen.

Normalizing, standardizing, and scaling processes are used to scale the variables in an ML model, such that they have the same order of magnitude in their value. Standardizing involves aligning the features to have a zero mean and scaled to have a standard deviation of 1 . Typically, RF models do not need standardizing or normalizing features due to the inherent bagging process (Breiman, 2001). At SGP $\mathrm{C} 1$, large diurnal variability was observed for certain parameters (like TKE, dissipation rate, etc.), leading to a large distribution of values between daytime and nighttime. This skewed the number of trees the RF model builds for daytime and nighttime estimates. Standardizing the features showed improvements while estimating nocturnal $z_{i}$ estimates from the RF model. Therefore, to improve nocturnal $z_{i}$ estimates, standardized datasets will be used in the following analysis for all conditions.

All the features, listed in Table 1, are filtered based on ARM mentor guidelines for each instrument and then normalized. These measurements are fed into an ensemble RF model using the hyperparameters described above. Once the RF model is built, a lasso regularization approach is used on the RF model to limit the effect of collinearity on the target variable. Similar to a least-squares regression, collinear columns tend to deteriorate the accuracy of the output (Krishnamurthy et al., 2013; Yoo et al., 2014). Once the RF model is built, it can be used to estimate $z_{i}$ for time periods that are not being used to train the model. In MATLAB, this is typically done using the predict function.

The RF model is trained using sub-surface, surface, lidar, and concurrent radiosonde $z_{i}$ data from 2016, 2017, and 2018. From here on, these data are referred to as traininginput features. A total of 3919 radiosonde $z_{i}$ measurements were used in the training process. The 2019 sub-surface, surface, and lidar data are referred to as future-input features and are used to provide an independent dataset to evaluate the trained RF method. From an operational perspective, missing input features are quite common. The most common approach is to fill in (impute) the missing features (Hastie et al., 2009). Surrogate data using a local median of the nearest 10 data points are used in the analysis (Hastie et al., 2009). Other imputation algorithms such as $k$-nearest neighbour were also tested, and similar results were observed. It is critical for the RF model to deal with missing values in its training phase. In some cases, the added noise in the system can help im- 
Table 2. Data imputation evaluation and performance on boundary layer heights for the year 2019.

\begin{tabular}{|c|c|c|c|c|c|}
\hline Case & Training-input features & Future-input features & $R^{2}$ & $\begin{array}{r}\text { RMSE } \\
(\mathrm{m})\end{array}$ & $Y_{\mathrm{RF}}=m X_{\mathrm{RS}}+C^{*}$ \\
\hline No imputation & No missing data & No missing data & $76.86 \%$ & 324 & $Y_{\mathrm{RF}}=0.912 X_{\mathrm{RS}}+211$ \\
\hline Future-input imputation & No missing data & $50 \%$ missing data imputed & $65.28 \%$ & 366 & $Y_{\mathrm{RF}}=0.789 X_{\mathrm{RS}}+288$ \\
\hline Training-input imputation & $50 \%$ missing data imputed & No missing data & $76.15 \%$ & 328 & $Y_{\mathrm{RF}}=0.876 X_{\mathrm{RS}}+258$ \\
\hline Training and future-input imputation & $50 \%$ missing data imputed & $50 \%$ missing data imputed & $66.50 \%$ & 357 & $Y_{\mathrm{RF}}=0.792 X_{\mathrm{RS}}+324$ \\
\hline
\end{tabular}

* RF - random forest; $\mathrm{RS}$ - radiosondes.

prove the stability of the RF model. But too much noise is also detrimental in the training process, and the imputed data may no longer be useful and can cause erroneous results. The imputation process is done inherently during the RF bagging process. The effect of data imputation on model performance was evaluated by training the RF model with and without data imputation. Four different possibilities in evaluating the performance of the RF model with and without imputation are evaluated, as shown in Table 2. In the case of no imputation (no missing data), only time periods when all features/parameters are available are used in the RF regression. In the case of $50 \%$ missing data, approximately $50 \%$ of the time series data were missing (at random) due to say issues with data quality, and surrogate data were used. The choice of $50 \%$ was to mimic a worst-case real-world scenario based on experience, where either one or two instruments from the feature set of 20 odd variables have data quality issues. Other combinations, such as no missing data used in the RF regression during the training process and $50 \%$ future-input feature missing data and vice versa, were evaluated.

As can be seen from Table 2, data imputation overall reduces the accuracy of RF model performance. Missing future-input features seems to have the highest effect on the RF model $z_{i}$ estimates, regardless of training the model based on missing training-input features. This could be due to several reasons, such as the fact that the median value does not represent the current state of the missing data, the same input features are not missing in both training and future input features as the combinations to test are near infinite (as the data in real-world scenarios can be missing in random as in the case above), etc. Assessing the performance of the RF algorithm using data imputation creates an additional level of complexity when one of the features is missing for a given time step compared to others. For example, if the relative humidity feature is missing for a given time step and lidar measurements are missing for another time step, the effect on the RF model output is not similar. The RF model provides weights to each feature, and the impact on the RF model would be dependent on the calibration and ability of the imputation algorithm to estimate the missing value. Since there are several possible scenarios here (as we have close to 20 odd features), and capturing all errors effectively would be a challenge, each feature is not weighted equally in the model. Therefore, in this analysis, the model is trained with no missing data, and no imputation is done on the data (either input or future features) to accurately test the efficacy of the RF model. The authors would like to note that the results in Sect. 4 are in some sense optimistic due to the treatment of missing data, and the worst-case performance of such an algorithm must be thoroughly evaluated. Future studies are planned to implement a better imputation model based on data from past trends for a given feature and to test RF model performance.

RF models are generally site specific; initial tests (not shown) show the possibility to develop a generalized RF model to estimate $z_{i}$ for all sites around SGP (C1 and other satellite sites) with good accuracy under all atmospheric conditions. A round-robin-type analysis, where a model developed at a given site is tested at every other site and vice versa, would be a valuable exercise (Bodini and Optis, 2020).

\section{Performance of RF $z_{i}$}

Boundary layer height predictions from the RF model and Tucker method were compared to radiosonde estimates. Mean absolute error (MAE) is defined as

$\mathrm{MAE}=\frac{1}{N} \sum_{i=1}^{N}\left|z_{i \mathrm{RS}}-z_{i \gamma}\right|$,

where $z_{i \mathrm{RS}}$ is the boundary layer height estimated from the radiosondes (Liu and Liang, 2010), and $z_{i \gamma}$ is the boundary layer height estimated from either the Tucker method or RF model. The root-mean-square error (RMSE) is defined as

$\mathrm{RMSE}=\sqrt{\frac{1}{N} \sum_{i=1}^{N}\left(z_{i \mathrm{RS}}-z_{i \gamma}\right)^{2} .}$

Similarly, the linear correlation coefficient $(R)$ is defined as

$R=\frac{1}{\sigma_{\mathrm{RS}} \sigma_{\gamma}(N-1)} \sum_{i=1}^{N}\left(z_{i \mathrm{RS}}-z_{\mathrm{RS}}\right)\left(z_{i \gamma}-z_{\gamma}\right)$,

where $z_{\mathrm{RS}}$ and $z_{\gamma}$ denote the mean of radiosonde and RF or Tucker method boundary layer heights, respectively, $\sigma_{\mathrm{RS}}$ 
Table 3. Systematic mean absolute errors, root-mean-square error, and correlation coefficient $\left(R^{2}\right)$ between RF, Tucker method, and radiosonde $z_{i}$ estimates in 2019.

\begin{tabular}{lrrr|rrr|rr}
\hline Observed & \multicolumn{3}{c}{ MAE $(\mathrm{m})$} & \multicolumn{2}{c|}{ RMSE (m) } & \multicolumn{2}{c}{$R^{2}$} \\
\cline { 2 - 8 } $\begin{array}{l}\text { atmospheric } \\
\text { conditions }\end{array}$ & RF & $\begin{array}{r}\text { Tucker } \\
\text { method }\end{array}$ & $\begin{array}{r}\% \\
\text { improvement }\end{array}$ & RF & $\begin{array}{r}\text { Tucker } \\
\text { method }\end{array}$ & $\begin{array}{r}\% \\
\text { improvement }\end{array}$ & $\begin{array}{r}\text { RF } \\
\text { Tucker } \\
\text { method }\end{array}$ \\
\hline Daytime only & 167 & 311 & $46 \%$ & 249 & 441 & $43 \%$ & 0.845 & 0.545 \\
Daytime clear sky & 165 & 336 & $51 \%$ & 235 & 479 & $51 \%$ & 0.857 & 0.520 \\
Daytime cloudy & 141 & 255 & $45 \%$ & 208 & 363 & $43 \%$ & 0.878 & 0.725 \\
\hline
\end{tabular}

and $\sigma_{\gamma}$ denote their standard deviations, and $N$ denotes the number of samples.

MAE and RMSE for the daytime atmospheric conditions from Tucker and RF methods are shown in Table 3. Daytime is defined as the period when surface heat flux is positive (i.e. sunrise to sunset), clear sky is defined as time periods when no clouds are observed from the Doppler lidar (with an hourly cloud fraction less than 0.1 ), and cloudy conditions are defined as time periods when clouds below $5 \mathrm{~km}$ are observed from the Doppler lidar (with an hourly cloud fraction greater than 0.1). It can be observed that the RF method shows considerable improvements compared to the Tucker method for all three categories. Improvements of $40 \%-50 \%$ in MAE and RMSE are observed under various conditions. The least improvement in $\mathrm{RF} z_{i}$ estimates is observed during cloudy conditions, with a MAE improvement of $45 \%$ compared to the Tucker method. Correlation coefficients are also observed to improve significantly during all daytime conditions.

Due to the presence of a nocturnal low-level jet (LLJ) at SGP, all seasons, the radiosonde nighttime $z_{i}$ estimates are generally below the LLJ height and are well tracked by the RF model (see Sect. 4.1). A comparison of nocturnal RF model $z_{i}$ estimates with other remote sensing devices that continuously monitor the boundary layer height needs to be conducted (e.g. Raman lidar) and is a part of future work.

Nocturnal estimates of $z_{i}$ from radiosondes at SGP are much more uncertain (Sivaraman et al., 2013). Regardless of the accuracy of the $z_{i}$ estimate from radiosondes, the ability of the RF model to predict the input data is evaluated. Consequently, the data were split into five atmospheric conditions: (1) daytime and clear sky (26\%), (2) day and night clear sky (60\%), (3) day and night cloudy (40\%), (4) daytime only (53\%), and (5) nighttime only (46\%). Although some cases overlap in the above situations, the idea was to evaluate the RF model performance reasonably during both daytime, nighttime, cloudy, and clear-sky condition combinations. These five atmospheric conditions were chosen, because these are commonly observed atmospheric conditions at SGP and have been observed to have an impact on $z_{i}$ (e.g. variations in cloud base height varies $z_{i}$ ). The associated correlation plots between $\mathrm{RF} z_{i}$ estimates and corresponding radiosonde $z_{i}$ estimates are shown in Fig. 5. Overall, the RF model $z_{i}$ estimates correlate well with radiosonde $z_{i}$, with an $R^{2}$ of greater than 0.85 during all the above conditions. During clear-sky conditions (including both daytime and nighttime), $\mathrm{RF} z_{i}$ estimates show the highest correlation of 0.88 . Although the sample size varied for five categories, the correlation coefficients are overall high for the $\mathrm{RF} z_{i}$ estimates (compared to Tucker method in Fig. 3). During the night, the $z_{i}$ values from the radiosondes are relatively constant, and the RF estimates are consistent with these values. However, due to the small dynamic range of the nighttime $z_{i}$ values, the correlation between the radiosonde and RF methods is relatively poor (0.54). Based on the slopes of the regression lines in Fig. 5, the RF model tends to overestimate $z_{i}$ when it is small and slightly underestimate $z_{i}$ when it is large. Possible reasons for this trend are under further investigation.

Overall, a uniform improvement in $z_{i}$ can be obtained using RF techniques. Reducing or increasing the training data had an impact on the RF model performance, but the increase in the magnitude of the correlation coefficient was negligible using at least 2 years of data. In this analysis, 3 years of data were used for training the RF model.

\subsection{Time series and diurnal and seasonal performance}

The RF model was trained using data from 2016 to 2018 , and $z_{i}$ estimates for 2019 were estimated using the parameters listed in Table 1. The temporal resolution of the RF model $z_{i}$ estimates is $15 \mathrm{~min}$. Figures 6 and 7 show lidar $z_{i}$ estimates from the Tucker method, radiosondes, and RF model on 20 and 22 June 2019, respectively. Cloud base height and vertical velocity variance profiles from Doppler lidar are also overlaid. Due to an ongoing field campaign, the micropulse differential absorption lidar demonstration project, these days observed a higher frequency of radiosonde observations (Weckworth et al., 2020). It is clear that the RF model $z_{i}$ closely follows radiosonde $z_{i}$ estimates, and the Tucker method underestimates $z_{i}$ as estimated from radiosondes. Although the Tucker method is observed to track the convective boundary layer height effectively, a bias is observed when compared to the radiosonde $z_{i}$. Optimizing the vertical velocity variance thresholds could potentially reduce the bias in certain conditions, but the bias is not uniform across all time periods (see Fig. 7). Because aerosol concentration de- 

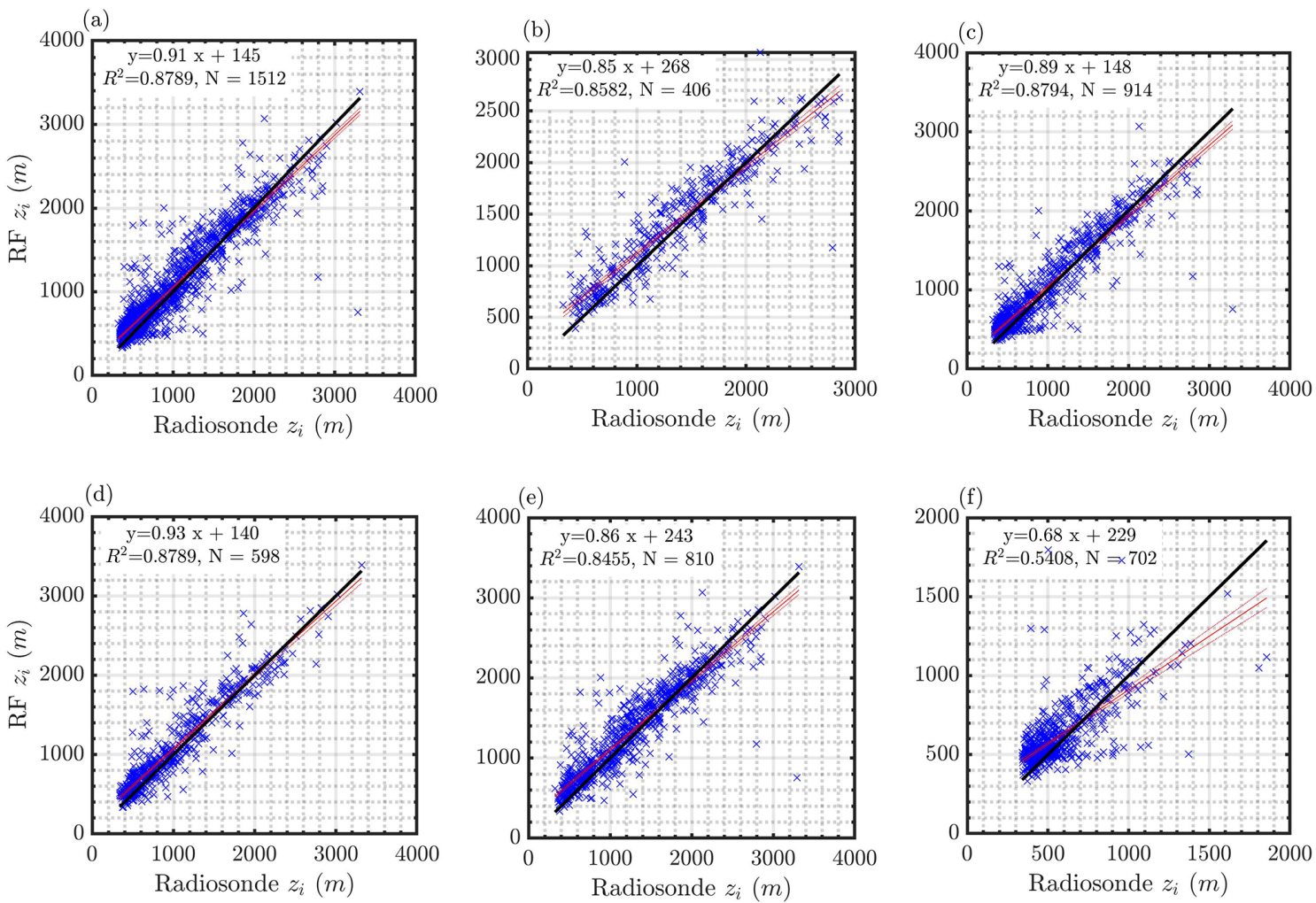

Figure 5. Correlations between RF PBL height and radiosonde PBL height for (a) all data in 2019, (b) daytime clear sky, (c) clear-sky daytime and nighttime, (d) cloudy daytime and nighttime, (e) daytime only, and (f) nighttime only.

creases with altitude, signal availability reduces as a function of height. During peak convection, when the aerosol concentration above the boundary layer is minimal, lidar measurements sometimes do not reach the top of the boundary layer with sufficient SNR to be detected. The lidar beam also attenuates considerably when it encounters clouds or fog due to increased atmospheric scattering or attenuation. In Fig. 6, it can also be seen that lack of aerosols limits the Doppler lidars' ability to measure above the boundary layer height during peak convective periods. During nighttime conditions, vertical velocity variance is low and is not effective in estimating $z_{i}$. In this study, the lowest range gate is used as the stable boundary layer height from the lidar as a first guess. As mentioned earlier, nocturnal conditions during summer months are dominated by southerly winds where the nocturnal boundary layer is capped by a low-level jet (Krishnamurthy et al., 2020). During these conditions, the RF model shows near-constant $z_{i}$, which is observed to be well correlated with radiosonde $z_{i}$ (just below the LLJ height).

In Fig. 7, the effectiveness of the RF model can clearly be observed. At 03:00 and 06:00 UTC, during stable nocturnal conditions, the RF model matches the radiosonde estimates very well. At 09:00 UTC, a possible nocturnal convection initiation event results in high vertical velocity variance for several hours (Reif et al., 2017). Convection ini- tiation refers to the process in which an air parcel is successfully lifted to its level of free convection and produces a precipitating updraft (Markowski and Richardson, 2010). The RF model is observed to detect that burst of convection and provide coherent boundary layer heights past 12:00 UTC until daytime transition at $\sim$ 14:00 UTC. The correlation between RF model and radiosonde $z_{i}$ estimates is very high. Therefore, various atmospheric interaction effects are aptly characterized by the parameters in the RF model. Hourly averaged $z_{i}$ and daily maximum $z_{i}$ averaged for each season in 2019 from the Tucker method, RF model, and radiosondes are shown in Fig. 8a. Although the number of samples between the radiosondes and RF model estimates are vastly different, the generic trend in the hourly and seasonal boundary layer height variability is well captured by the RF model. Although the Tucker method captures the average boundary layer height trend, it shows a clear bias in convective boundary layer height estimates compared to radiosonde- and RFmodel-derived $z_{i}$ values. As observed earlier from the time series analysis, a standard bias correction would not always improve $z_{i}$ estimates from the Tucker method. Daily daytime maximum $z_{i}$ estimates averaged over four seasons in 2019 from all three methods are shown in Fig. 8b. Summer months (May through August) show high boundary layer heights. During these months, the peak convective period oc- 


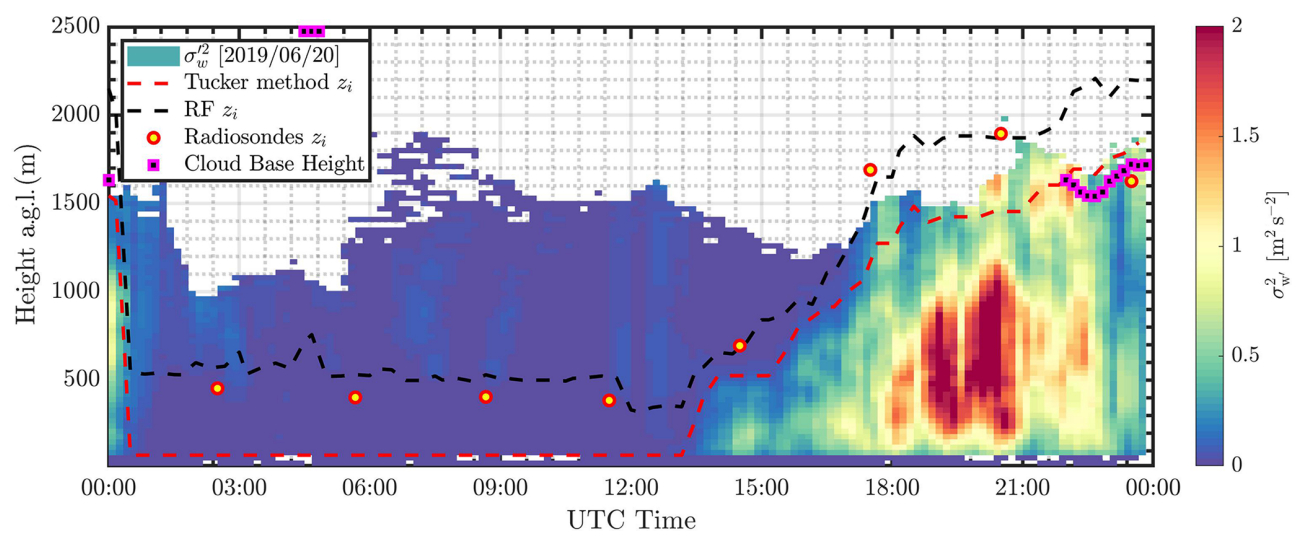

Figure 6. Boundary layer height estimates at the SGP central facility on 20 June 2019 from the Tucker method (Tucker et al., 2009), RF model $z_{i}$, radiosondes $z_{i}$ (Sivaraman et al., 2013), cloud base height estimates from lidar (Newsom et al., 2019b), and the background colours represent vertical velocity variance measurements from Doppler lidar.

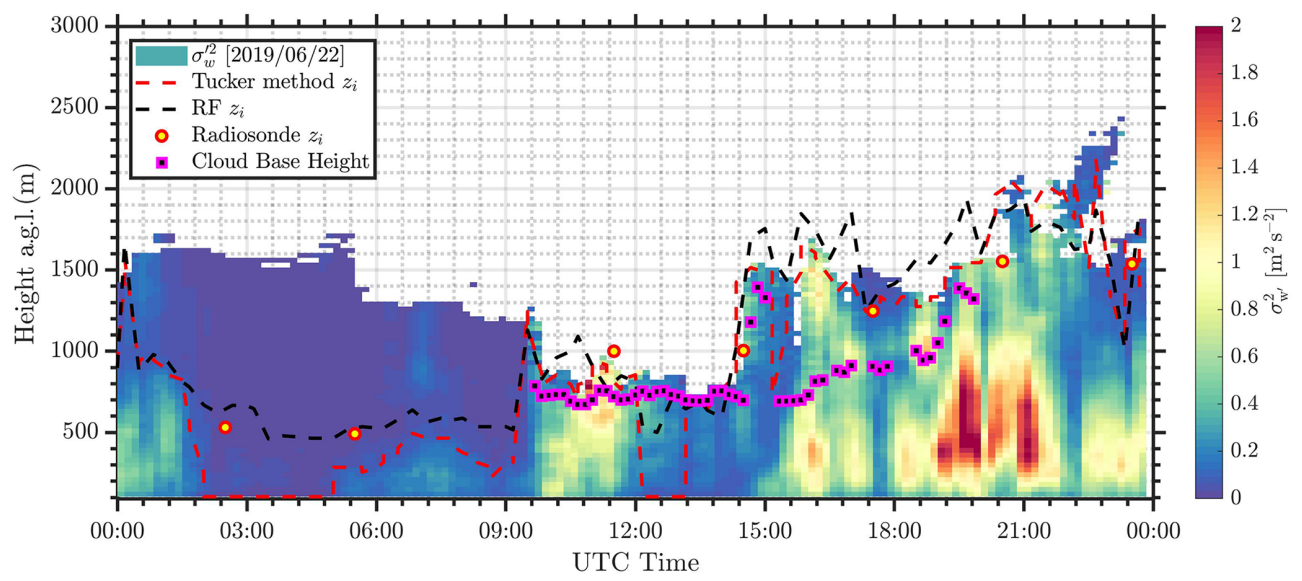

Figure 7. As in Fig. 6, but for 22 June 2019.

curs during the daytime at around 20:00 UTC, and the average boundary layer height as observed from the RF model is $\sim 2100 \mathrm{~m}$ above ground level, which correlates well with radiosondes released during the same time period. During winter and autumn months, the peak convective period does not always occur at 20:00 UTC, and therefore the maximum $z_{i}$ estimates from radiosondes do not coincide with RF estimates. The Tucker method invariably underestimates maximum $z_{i}$ during all seasons.

\subsection{Input feature importance}

All the input features within the RF model explain approximately $82 \%$ of the total variance in the data. Table 4 provides the unbiased predictor importance estimates, which is computed by permuting or shuffling a variable in the model and estimating its mean square error (Breiman, 2001). If a predictor is significant in prediction, then permuting its values will affect the model error and vice versa. However, if two input variables are highly correlated (as is expected when testing atmospheric forcing), it is highly unlikely that the reported importance values will accurately represent each variable's significance (Breiman, 2001). Based on this analysis, the most important parameter is the initial $z_{i}$ guess from the Tucker method. This provides a very good first guess to the RF model, especially during convective conditions. Although the RF model is sensitive to the initial guess from the Tucker method, it is observed to be robust enough to ignore uneven spikes in $z_{i}$ estimates due to noise in the lidar vertical velocity variance data (Fig. 7). The second most important feature observed to have high correlation with $z_{i}$ estimate is the hour of the day. A clear diurnal pattern in $z_{i}$, i.e. higher values in the daytime and near-constant values during the nighttime, estimates is observed at SGP. Therefore, hour of the day can effectively classify the data, which is beneficial in the RF bagging process. Relative humidity also shows higher importance $(>5 \%)$, where drier conditions are observed to have higher correlations with boundary layer height. Deep convection and larger $z_{i}$ is generally a consequence of greater sensible heat flux and lower latent heat flux, which are primarily 

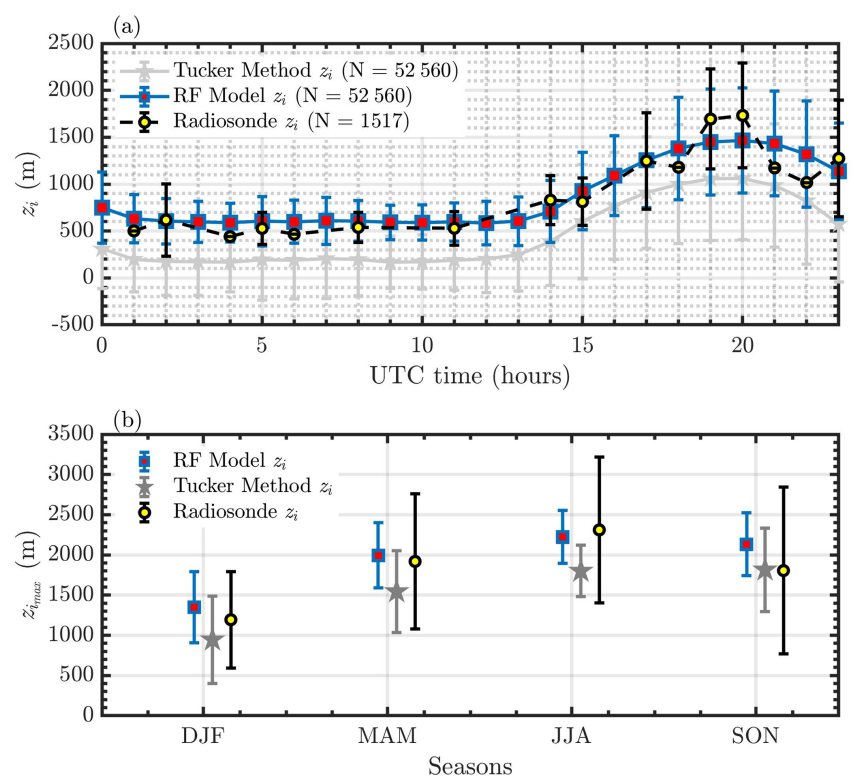

Figure 8. (a) Hourly averaged $z_{i}$ estimates at the SGP central facility for 2019 from RF, the Tucker method, and radiosondes. Total number of samples $(N)$ for each dataset is also shown in the legend. (b) Daily daytime maximum $z_{i}$ estimates for four seasons (DJF, MAM, JJA, SON) from RF, radiosonde, and the Tucker method. The bars in both plots represent 1 standard deviation.

due to higher surface temperature and lower relative humidity. Based on an evaluation of $z_{i}$ over Europe, it was also observed that relative humidity had a strong negative correlation with $z_{i}$, and surface temperature had a positive correlation (Zhang et al., 2013). Other features such as lidar attenuated backscatter, surface air temperature, Monin-Obukhov length, soil temperature, surface wind direction, and TKE are all observed to be important for accurately characterizing the boundary layer height at SGP. Other surface features such as surface friction velocity, sensible heat flux, longwave radiation, etc., have lower correlations with $z_{i}$ within the RF model framework. Therefore, the model can be reduced to the list of parameters defined in Table 4 for optimal estimation of the boundary layer height at SGP.

To assess the key features during nighttime, a similar RF model was built by conditionally sampling nighttime data. During nighttime, the key parameters that affect the RF model predictions are shown in Table 5. It is interesting to note that the key features deemed important during nighttime are significantly different compared to all conditions, and the percent importance is more evenly distributed across many features. This result alludes to the fact that nocturnal stable boundary layers are indeed complex to model, and several processes are at play (Fernando and Weil, 2010). MoninObukhov length is observed to have the highest impact on the nighttime RF model estimates and is consistent with theory on stable boundary layers (Zilitinkevich, 1972; Zilitinkevich and Baklanov, 2002). Although nighttime $z_{i}$ initial guesses
Table 4. Key parameter/feature unbiased importance estimates during all conditions.

\begin{tabular}{lr}
\hline Parameters/features & $\%$ importance \\
\hline Tucker method $z_{i}$ & $58.67 \%$ \\
Hour of the day & $10.05 \%$ \\
Surface relative humidity & $6.82 \%$ \\
Attenuated backscatter & $2.90 \%$ \\
Surface air temperature & $2.77 \%$ \\
Monin-Obukhov length & $2.77 \%$ \\
Soil temperature & $1.92 \%$ \\
Surface wind direction & $1.78 \%$ \\
Turbulence kinetic energy & $1.32 \%$ \\
Others & $<11 \%$ \\
\hline
\end{tabular}

are generally a constant (lowest lidar range gate if no high vertical velocity variance is observed), the initial guess has shown to be effective in adjusting the RF model $z_{i}$ estimates. Other local parameters such as soil temperature, surface air temperature, dew point temperature, longwave radiation, and turbulence kinetic energy are observed to be correlated with nighttime $z_{i}$ estimates. One of the stable boundary layer models by Brost and Wyngaard (1978) is given by

$z_{i}=0.4\left(\frac{u_{*} L}{|f|}\right)^{1 / 2}$,

where $u_{*}$ is the friction velocity, $L$ is the Monin-Obukhov length, and $f$ is the Coriolis parameter. As shown in Table 5 , the nighttime parameters deemed important by the RF model include both Monin-Obukhov length and friction velocity. As discussed earlier, the dominant feature of nocturnal boundary layer at SGP is the presence of the LLJ. The turbulence production at SGP is not only influenced by surface characteristics but also heavily influenced by the presence of the LLJ. A preliminary comparison with the above model to RF model $z_{i}$ estimates at SGP was very poor, as the radiosondes (from all three methods) invariably pick up the nocturnal LLJ at SGP as the height of the boundary layer. Although the height of the nocturnal boundary layer height could be debatable at SGP, the premise of this paper is to show the effectiveness of the RF model in tracking and detecting the boundary layer height and the input boundary layer height provided to the model. Further research needs to be conducted on providing widely acceptable nocturnal boundary layer height at SGP, and a trained RF model can provide continuous boundary layer height estimates even in nocturnal conditions with acceptable levels of accuracy.

The partial dependence of key features on $z_{i}$ during all conditions is shown in Fig. 9. Partial dependence estimates show the marginal effect of features on the predicted outcome of an ML model. Therefore, a higher partial dependence estimate corresponds to higher sensitivity to the predicted outcome, in our case the boundary layer height and vice versa. From Fig. 9, we see that RF model $z_{i}$ is sen- 

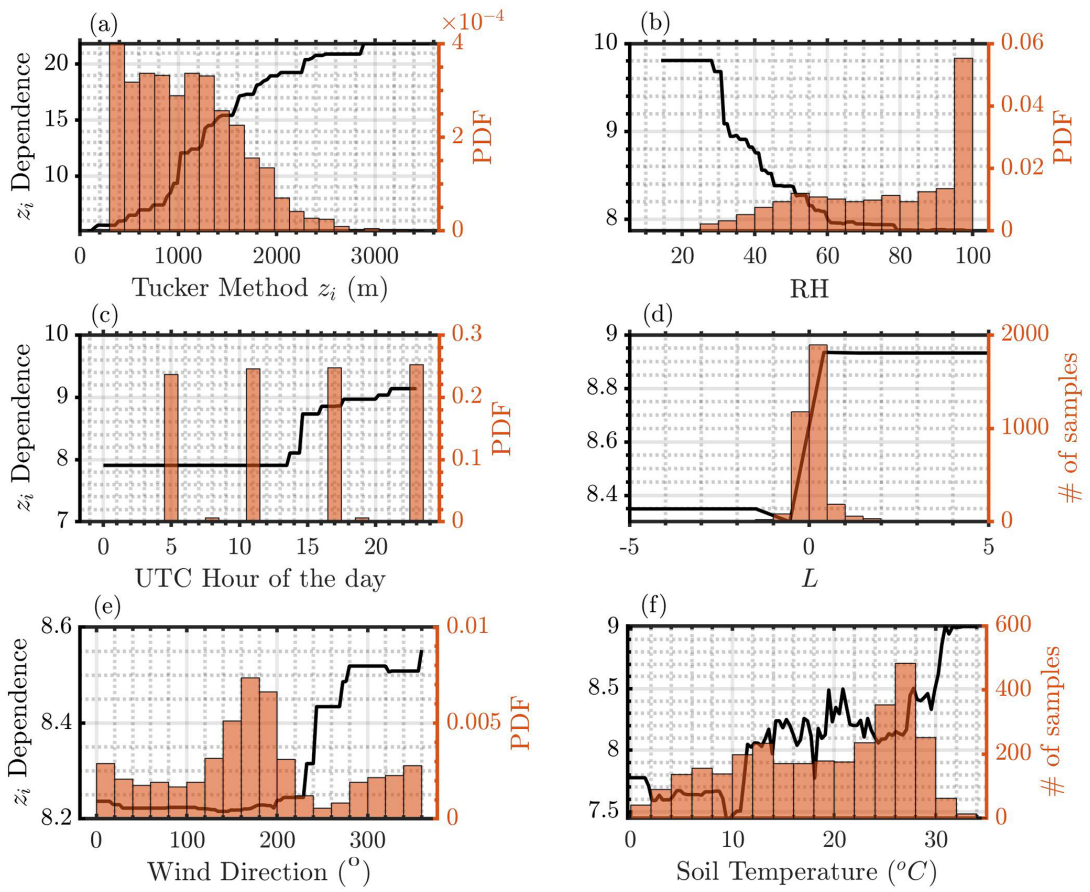

Figure 9. RF partial dependence during all conditions from (a) the Tucker method $z_{i}$, (b) relative humidity, (c) hour of the day, (d) MoninObukhov length, (e) surface wind direction, and (f) soil temperature to boundary layer height at the central facility. High dependence shows more sensitivity of the RF model to the bin of feature values.

Table 5. Key parameter/feature unbiased importance estimates during nighttime conditions.

\begin{tabular}{lr}
\hline Parameters/features & $\%$ importance \\
\hline Monin-Obukhov length & $19.12 \%$ \\
Tucker method $z_{i}$ & $11.49 \%$ \\
Soil temperature & $7.81 \%$ \\
Surface air temperature & $7.56 \%$ \\
Dew point temperature & $6.31 \%$ \\
Longwave radiation & $6.24 \%$ \\
Turbulence kinetic energy & $5.21 \%$ \\
Net radiation & $4.72 \%$ \\
Surface wind speed & $4.28 \%$ \\
Surface wind direction & $3.76 \%$ \\
Lidar dissipation rate variance & $3.54 \%$ \\
Surface friction velocity & $3.45 \%$ \\
Cloud base height & $3.40 \%$ \\
Shortwave radiation & $3.26 \%$ \\
Others & $<10 \%$ \\
\hline
\end{tabular}

sitive to warmer soil temperatures, lower-relative-humidity conditions, daytime hours, higher $z_{i}$ from the Tucker method, northerly wind directions, and stable atmospheric conditions. Most of these conditions would mimic dry convective conditions, with increased turbulence activity within the boundary layer. Monin-Obukhov length is observed to effectively categorize the training data into stable and unstable atmo- spheric conditions, with high partial dependence estimates during stable boundary layer conditions. Similar relationships can be derived for other parameters. It is important to note that the parameters shown to be important with respect to the RF model are features that successfully aid in the RF bagging process. Santenello et al. (2007) and Tang et al. (2018) showed parameters such as soil moisture and evaporative flux to be key variables in warm seasons, in a two-parametric regression framework, that affect boundary layer properties. Within the RF model, although those parameters are deemed important, soil temperature, lidar backscatter, and relative humidity were shown to have a higher impact on boundary layer height at each site.

In this research, the input features into the RF model are standard atmospheric parameters (such as wind speed, temperature, etc.). An alternate approach to this effort would be to provide several non-dimensional inputs (such as bulk Richardson number, Obukhov length scale, ratio of BruntVäisälä frequency to the Coriolis parameter, etc.) as inputs because they capture multiple dimensions of the data with a single variable (Vassallo et al., 2020, 2021). Because nondimensional scaling is a common approach in atmospheric fluid dynamics to detect patterns in the data, a similar approach would provide the RF model with various relations and be helpful in classifying the data better. But further research needs to be conducted in defining the key nondimensional parameters that affect $z_{i}$ at SGP and is a part of future work. 


\section{Normalized vertical velocity variance profiles}

Within a convective boundary layer, vertical velocity variance profiles are often scaled by the convective velocity scale $\left(w^{*}\right)$, which is a function of $z_{i}$ (Lenschow et al., 1980) for analysis. Therefore, any error in $z_{i}$ estimates can result in altering the vertical velocity variance profiles. Herein, we attempt to estimate the effect of $z_{i}$ on normalized vertical velocity variance profiles and convective velocity estimates, often used to compare results in boundary layer studies and in the functional relationships used in atmospheric models. The convective velocity scale is given as

$w^{*}=\left[\frac{g z_{i} \overline{w^{\prime} \theta^{\prime}}}{\theta}\right]^{1 / 3}$,

where $g$ is the gravitational constant, $\theta$ is potential temperature, and $\overline{w^{\prime} \theta^{\prime}}$ is heat flux. The heat flux is obtained from the surface eddy covariance system at SGP C1 (Cook, 2018a), and potential temperature is measured at $4 \mathrm{~m}$. An uncertainty in $z_{i}$ will cause a non-linear effect in the convective velocity scale estimates. Assume the uncertainty in $z_{i}$ can be given as $z_{i}^{\prime}$, and the mean is given as $\overline{z_{i}}$. The error caused in the convective velocity scale due to uncertainty in $z_{i}$ can be formulated as shown below:

$w^{*}=\left[\frac{g\left(\overline{z_{i}}+z_{i}^{\prime}\right) \overline{w^{\prime} \theta^{\prime}}}{\theta}\right]^{1 / 3}$.

This can also be written as

$w^{*}=\left[\frac{g \overline{z_{i}} \overline{w^{\prime} \theta^{\prime}}}{\theta}\right]^{1 / 3}\left(1+\frac{z_{i}^{\prime}}{\overline{z_{i}}}\right)^{1 / 3}$.

Therefore, the convective velocity scale error due to uncertainty in $z_{i}$ can be estimated using the term $(1+x)^{1 / 3}$, where $x=\frac{z_{i}^{\prime}}{z_{i}}$. Based on observations at SGP C1, $z_{i}$ from the Tucker method is observed to be negatively biased to radiosonde estimates. The ratio, $\left(\frac{z_{i}^{\prime}}{z_{i}}\right)$, is calculated using the median error between Tucker method and RF model $z_{i}$ by the median $z_{i}$ using the RF model. The ratio is calculated to be approximately -0.28 for data from 2016 to 2019 . This would result in an uncertainty of approximately $10 \%$ in the convective velocity estimates when Tucker method $z_{i}$ values are used in the calculations. Although this is an average, during certain conditions (e.g. during transition time periods) the effect of poor characterization of $z_{i}$ can be even larger. Figure 10 shows average vertical velocity variance profiles during convective time periods at SGP from 2015 to 2019 using $z_{i}$ estimates from the Tucker method and RF model. Higher $z_{i}$ values result in lower scaled vertical velocity variance estimates. Differences in variance profiles are observed to be smaller during daytime transition (15:00 UTC or 09:00 LT), as the Tucker method generally provides reliable
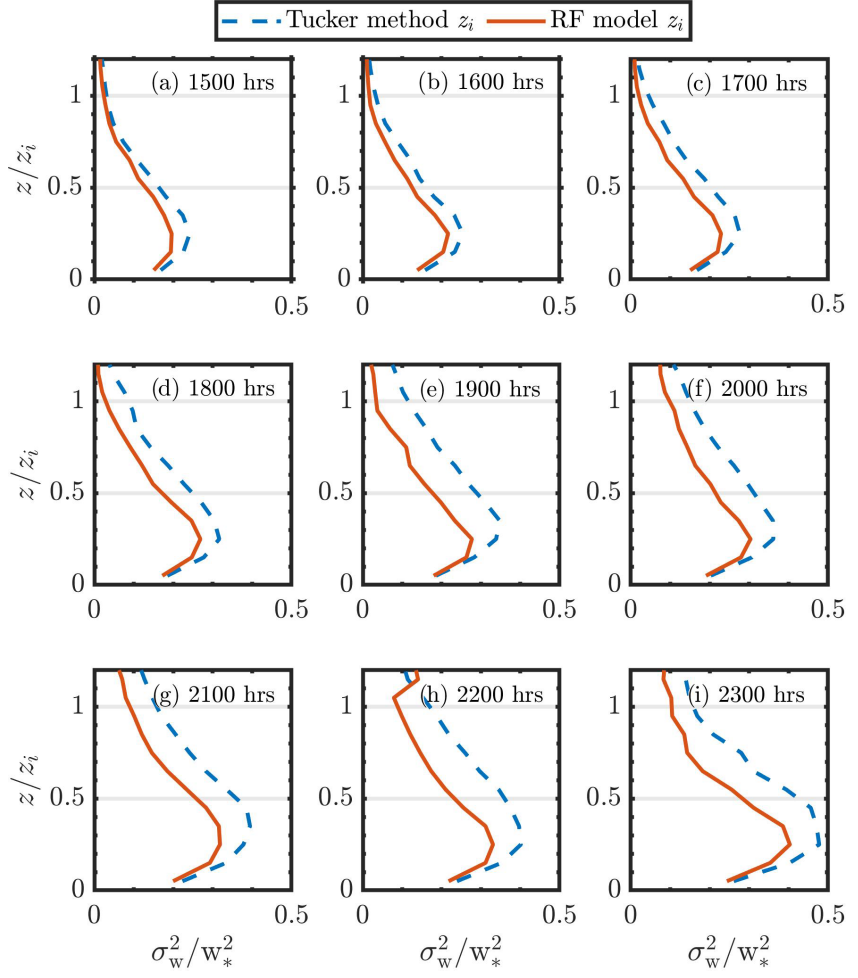

Figure 10. Average normalized vertical velocity variance profiles during convection periods (15:00 to 23:00 UTC, a-i) at SGP from 2015 to 2019 versus non-dimensional height using $z_{i}$ estimated by the Tucker method and RF model. Appropriate $z_{i}$ (RF model or Tucker method) was used in both $x$ - and $y$-axis scaling.

$z_{i}$ estimates. During peak convective conditions (20:00 UTC) and evening transition (23:00 UTC), as observed earlier, the Tucker method $z_{i}$ estimates tend to diverge from radiosonde $z_{i}$ depending on the scenario and are negatively biased. Overall, the error introduced in the scaled vertical velocity variance profiles due to Tucker method $z_{i}$ is above $15 \%$.

As per definition, the turbulence at the top of the boundary layer is expected to be near zero, except during cloudy conditions. As shown in Fig. 10, during morning transition periods, when the lidar does measure above the boundary layer, the scaled vertical velocity variance profiles do converge to zero. In contrast, during peak convective conditions the scaled profiles do not converge to zero and are observed to have an offset of generally around 0.1 at $z_{i}$ (also observed in Lareau et al., 2018). This could be due to higher uncertainty in lidar vertical velocity variance estimates near $z_{i}$, ineffective filtering of the lidar false alarm rates (Bouquet et al., 2016), uncertainty in surface in situ measurements, and the possibility of residual turbulence above the boundary layer during downdrafts or updrafts. 


\section{Case study: preliminary model comparisons}

We expect the RF model $z_{i}$ outputs to be developed into a VAP that will be easily accessible and can be used by researchers across the community. Therefore, the motivation for this case study is to provide a preliminary comparison between model-estimated $z_{i}$ and the RF model $z_{i}$. These types of comparisons will help understand the impact of boundary layer properties on model physics and guide further in improving parameterizations used to represent boundary layer turbulence.

The surface and sub-surface layer measurements are key for understanding land-atmosphere interactions. Landatmosphere interactions drive Earth's surface water and energy budgets. They can alter clouds and precipitation around a region, affect the growth of the planetary boundary layer height, and influence the persistence of extremes such as droughts. In view to better understand land-atmosphere interactions, a field campaign, Holistic Interactions of Shallow Clouds, Aerosols and Land Ecosystems (HI-SCALE), was conducted at the SGP site in Oklahoma (Fast et al., 2019). The field campaign was conducted from April to September of 2016, with two 4-week intensive observational periods in May and September. Simulations were conducted on select clear-sky days during the HI-SCALE field campaign. Two simulations using different modelling systems were performed: Energy Exascale Earth System Model (E3SM; Golaz et al., 2019) Atmosphere Model version 1 (EAMv1; Rasch et al., 2019) and a LES model. The Weather Research Forecasting (Skamarock et al., 2008) LES is set up in the same way as that used in operational LASSO (Gustafson et al., 2017, 2020). The Weather Research Forecasting model version used is v3.7. The model horizontal domain is square, doubly periodic, and $25.6 \mathrm{~km}$ wide with a $100 \mathrm{~m}$ horizontal grid spacing. The model top is set at $14.8 \mathrm{~km}$ above the surface. There are 226 vertical levels with a vertical grid spacing of $\sim 30 \mathrm{~m}$ in the lowest $5 \mathrm{~km}$. The model is run for $15 \mathrm{~h}$ for each case day starting at 06:00 UTC. The Rapid Radiation Transfer Model for Global Climate Models parameterization is used for shortwave and longwave radiation (Clough et al., 2005; Iacono et al., 2008; Mlawer et al., 1997). The Thompson parameterization is used for microphysics (Thompson et al., 2004, 2008). The Deardorff 1.5-order turbulent kinetic energy approach is used for subgrid-scale parameterization (Deardorff, 1980). The model is initialized with ARM sounding from the SGP site (ARM user facility, 2001). The surface sensible and latent heat fluxes are horizontally uniform and prescribed from the ARM constrained variational analysis data product (ARM user facility, 2004). The largescale forcing is also taken from the ARM variational analysis data product. Due to high computational expense, the LES model was run for $3 \mathrm{~d}$ while the EAMv1 model was run for the entire duration of the HI-SCALE campaign. The EAMv1 model is run in the standard coarse-resolution configuration with $\sim 1^{\circ}$ horizontal grid spacing and 72 vertical levels and a physics time step of $30 \mathrm{~min}$ and a cloud and turbulence time step of $5 \mathrm{~min}$. In these models, $z_{i}$ was estimated using resolved vertical velocity variance estimates from the LES or the parameterized vertical velocity estimate from the Cloud Layers Unified by Binormals (CLUBB) boundary layer parameterization applied in E3SM (Golaz et al., 2002; Larson and Golaz, 2005; Bogenshutz and Krueger, 2013; Larson, 2017), and like the Tucker method a low threshold was used to estimate the depth of the convective boundary layer. Estimates of boundary layer height from E3SM and LASSO were not made during nocturnal conditions. The LASSO simulations extend only from approximately sunrise to sunset, so nocturnal estimates of the boundary layer height are not possible. The E3SM simulations generally have too much nighttime turbulence, making estimates of the boundary layer height unreliable at night.

Figure 11 shows Doppler lidar vertical velocity variance measurements for $3 \mathrm{~d}$ during the HI-SCALE campaign (1012 September 2016) and boundary layer height estimates from RF model, radiosondes, LASSO, and E3SM. Because the RF model provides $z_{i}$ estimates at a much finer temporal resolution than radiosondes, these estimates are ideal for comparing with models and assessing areas where model performance can be improved. Therefore, in this preliminary comparison, the primary motivation is to see if we can identify areas where the models diverge significantly by using near-continuous accurate $z_{i}$ values from the RF model. Due to computational expense, we could evaluate only $3 \mathrm{~d}$ of model results, but further research is needed in performing a thorough evaluation.

Conditions on 10 September were relatively calm with northerly winds, and no clouds were observed during daytime. On 11 and 12 September, there were southerly winds and clear-sky conditions during both daytime and nighttime. Daytime maximum surface air temperature is observed to increase progressively from 10 to 12 September, and as mentioned earlier higher air temperature results in deeper planetary boundary layer due to increased convection (see Fig. 11).

Overall, the LES model compares better to RF estimates, while EAMv1 is observed to underestimate $z_{i}$. Due to the coarse resolution of EAMv1, $\sim 100 \mathrm{~km}, z_{i}$ estimates are averaged over a large domain and do not generally capture the fine-scale variability. Although the LES model is observed to pick up morning transition, it diverges from observations during evening transitional periods and does not capture the decay of turbulence accurately. During peak convective conditions, when the vertical velocity variance is large, the LES is observed to correlate very well with the RF model and radiosonde $z_{i}$. Although EAMv1 is observed to mostly underestimate $z_{i}$ compared to RF model estimates, occasionally the model captures the peak convective trends. Like the LES model $z_{i}$, the EAMv1 is also not observed to capture evening decay of turbulence accurately but is observed to not track the early morning transition at SGP as well. Such systematic differences between the model and data are crucial for tar- 


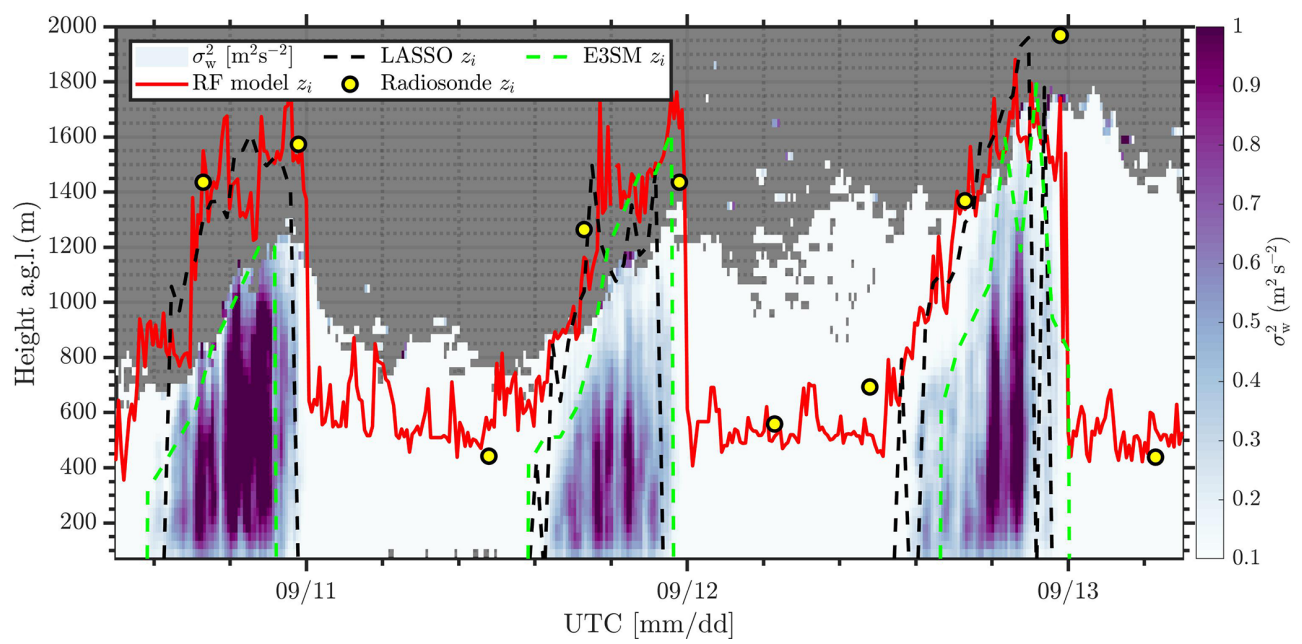

Figure 11. Vertical velocity variance $\left(\sigma_{\mathrm{w}}^{2}\right)$ estimates from Doppler lidar for $3 \mathrm{~d}\left(10,11\right.$, and 12 September 2016) with $z_{i}$ estimates from (a) the RF model (red solid line), (b) radiosondes (yellow circles), (c) the LASSO model (black dashed line), and (d) the E3SM model (green dashed line).

geting future research directions. Further study is needed to evaluate the reasons why models tend to deviate during early morning and/or evening transition periods.

\section{Summary}

This study used a range of near-surface, sub-surface and Doppler lidar parameters to predict boundary layer heights at the ARM SGP site using an RF model. The RF model was trained using several years of data, and the model was validated with radiosonde estimates of boundary layer height. Because the Tucker method is observed to be low biased during peak convective periods due to low SNR of the Doppler lidars as the boundary layer deepens, the RF model corrects for the bias. Seasonal and diurnal variations in $z_{i}$ as observed from radiosondes correlate well with RF model $z_{i}$. During convective boundary layer conditions, the mean absolute error of boundary layer height estimated by the RF model is reduced by almost $50 \%$ compared to the Tucker method. Significant improvement was also observed during clear-sky and cloudy conditions. Nocturnal estimates from the RF model were not well correlated with radiosonde measurements, mostly due to near-constant estimates of nocturnal boundary layer height at SGP (due to the presence of the LLJ). Moreover, valuable information on the impact of surface parameters on nocturnal $z_{i}$ estimates by the RF model provides avenues for further research in accurately estimating stable boundary layer heights at SGP. The key variables that have shown to have the largest impact on the RF model predictions are the initial guess of the boundary layer height from the Tucker method, hour of day, surface relative humidity, soil temperature, and attenuated backscatter (aerosol loading). During nocturnal conditions, several parameters, such as the Monin-Obukhov length, soil temperature, and surface air temperature, influence the RF model estimates. These parameters are aligned with theoretical parameterization schemes used to estimate boundary layer heights. The RF model used in this study explains around $82 \%$ of the variance in the data at SGP C1.

Uncertainty in convective boundary layer heights results in more than $10 \%$ difference in convective velocity scale estimates when the Tucker method is used. The uncertainty results in more than $15 \%$ error in scaled velocity variance estimates, which are commonly used in atmospheric models. Limited comparison between microscale model $z_{i}$ estimates of the RF model and radiosonde $z_{i}$ values show increased correlation during heightened land-air interaction events. Large-eddy simulation estimates are observed to match the convective $z_{i}$ variability as estimated by the RF model while the global model performance is variable. Neither model captures the evening transitional decay of turbulence accurately.

There are a number of ways to expand on the research presented here. Future work could focus on improved data imputation models to better handle missing data, a RF model $z_{i}$ uncertainty framework using individual RF tree predictions, and finally a study of the effect of nearby wind farms and surface heterogeneity have on the boundary layer height. 


\section{Appendix A}

The range availability of the ARM SGP C1 Doppler lidars used in this study is provided below. Figure A1 shows the height range and data availability at SGP C1 for vertical stare scans and Fig. A2 for processed velocity azimuth display (VAD) scans. The lidar range is consistent across multiple years of operation. The availability of data from the scanning Doppler lidars at SGP C1 is significantly reduced for altitudes greater $1 \mathrm{~km}$ (60\% availability), which could limit its ability to reach the top of the boundary layer during all conditions.

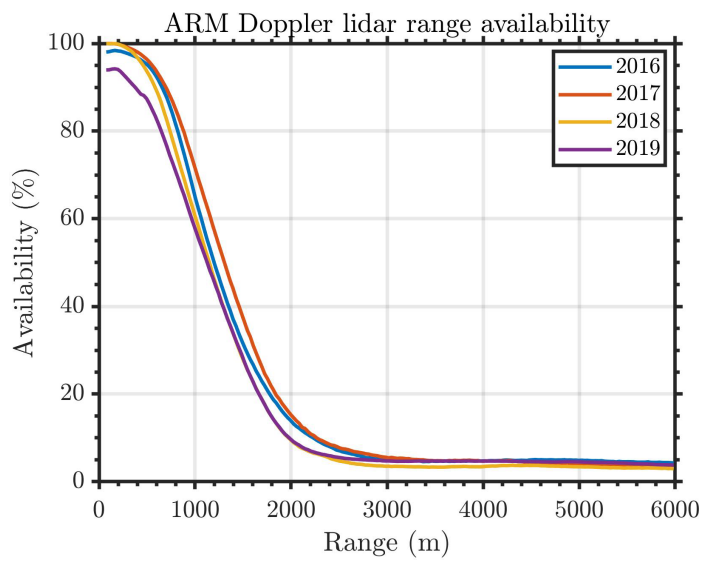

Figure A1. ARM SGP C1 Doppler lidar range availability versus range from vertical stares from 2016 to 2019 after SNR filtering (threshold of $1.008 \mathrm{~dB}$ ).

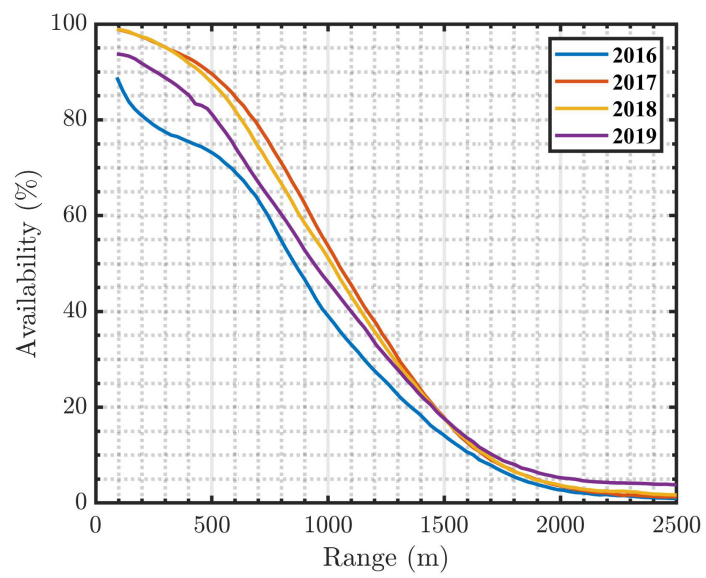

Figure A2. ARM SGP C1 Doppler lidar wind speed profile range availability versus range using processed VAD scans from 2016 to 2019 after SNR filtering (threshold of $1.008 \mathrm{~dB}$ ). 


\section{Appendix B}

The RF model develops several regression trees by regrouping the data based on several input features. Figure B1 below shows one of the trees developed by the model used in this article. The leaf nodes are the $z_{i}$ estimates from radiosondes, and the split nodes represent the surface and lidar data shown in Table 1. MATLAB built-in functions were used for the development of the RF model.

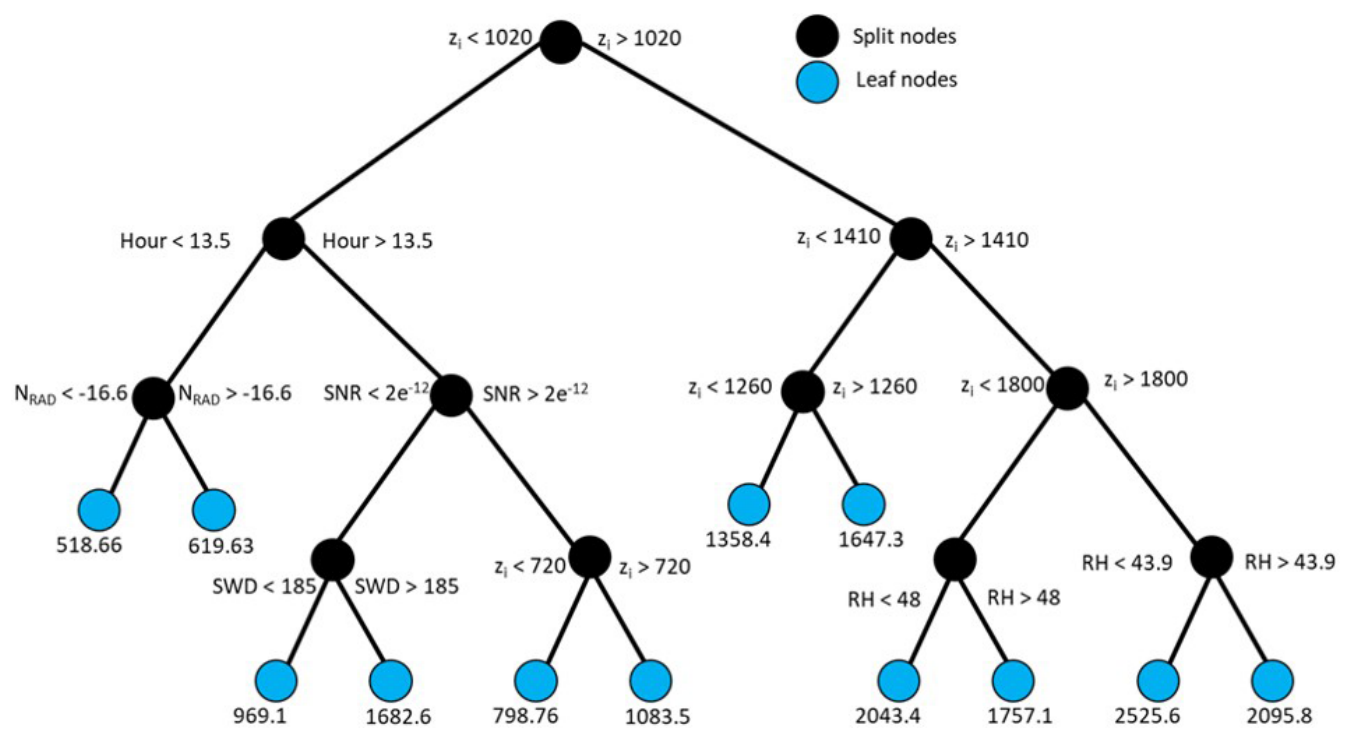

Figure B1. A sample regression tree developed by the RF model. $z_{i}$ is the Tucker method boundary layer height estimate, SNR is signalto-noise ratio, NRAD is the normal radiation, RH is relative humidity, SWD is surface wind direction, Hour is hour of the day. The black circles represent the split nodes, and the cyan circles represent the leaf nodes developed for this regression tree (a.k.a. boundary layer height estimates from radiosondes). 
Data availability. All data used in this article are publicly available on the ARM web page (https://adc.arm.gov/discovery/\#/, last access: 30 March 2021). Appropriate labels and manual citations for all the data used are provided in the manuscript. Measurements of winds and turbulence from a Doppler lidar (https://doi.org/10.5439/1025185, Newsom and Krishnamurthy, 2020), surface fluxes from a sonic anemometer at $25 \mathrm{~m}$ on the $60 \mathrm{~m}$ meteorological tower (https://adc.arm.gov/ discovery/\#/results/datastream::sgpco2flx25mC1.b1, Biraud et al., 2015), meteorological measurements from a surface meteorological tower (https://doi.org/10.5439/1025220, Kyrouac et al., 1993), radiation measurements from the surface energy budget station (https://doi.org/10.5439/1025274, Sullivan et al., 2010), soil temperature and moisture from soil probes at $5 \mathrm{~cm}$ depth (https://doi.org/10.5439/1256098, Cook et al., 2016), and boundary layer height estimates from radiosondes at SGP central facility (https://doi.org/10.5439/1150253, Riihimaki et al., 2001) are used in this article.

Author contributions. RK and RKN conceptualized the concept; RK, RKN, and DDT were involved in the development of the algorithm; RK did the data processing and analysis of the RF algorithm, surface stations, lidar, and radiosonde results; HX performed the large-eddy simulation runs; PLM performed the E3SM runs; LKB calculated the boundary layer height from model outputs; and RK wrote the manuscript with contributions from all authors.

Competing interests. The authors declare that they have no conflict of interest.

Acknowledgements. The authors would like to acknowledge the support of Atmospheric Radiation Measurement (ARM) User Facility and the Atmospheric System Research (ASR) programme for this research. The authors thank the ARM staff and instrument mentors for providing processed data and guidance on the data archive. The authors also thank Duli Chand (PNNL), Joe Hardin (PNNL), and Christina Kumler (NOAA) for helpful discussions and comments on the manuscript. The Pacific Northwest National Laboratory is operated for the U.S. Department of Energy by Battelle under contract DE-AC05-76RL01830.

Financial support. This research has been supported by the U.S. Department of Energy, Atmospheric Radiation Measurement and Atmospheric Science Research program (grant no. DE-AC0576RLO1830).

Review statement. This paper was edited by Domenico Cimini and reviewed by two anonymous referees.

\section{References}

Atmospheric Radiation Measurement (ARM) user facility: BalloonBorne Sounding System (SONDEWNPN). Southern Great Plains (SGP) Central Facility, Lamont, OK (C1), updated hourly, compiled by: Keeler, E., Ritsche, M., Coulter, R., Kyrouac, J., and Holdridge, D., ARM Data Center, https://doi.org/10.5439/1021460, 2001.

Atmospheric Radiation Measurement (ARM) user facility: Constrained Variational Analysis (60VARANARUC). Southern Great Plains (SGP) Central Facility, Lamont, OK (C1), compiled by: Tao, C. and Xie, S., ARM Data Center, https://doi.org/10.5439/1647300, 2004.

Banakh, V. A., Smalikho, I. N., and Falits, A. V.: Estimation of the height of the turbulent mixing layer from data of Doppler lidar measurements using conical scanning by a probe beam, Atmos. Meas. Tech., 14, 1511-1524, https://doi.org/10.5194/amt14-1511-2021, 2021.

Berg, L. K., Newsom, R. K., and Turner, D. D.: Year-long vertical velocity statistics derived from Doppler lidar data for the continental convective boundary layer, J. Appl. Meteorol. Clim., 56, 2441-2454, 2017.

Biraud, S., Billesbach, D., and Chan, S.: ECOR: 30-minute averaged surface vertical fluxes of momentum, sensible heat, and latent heat at Southern Great Plains central facility, DOE Office of Science Atmospheric Radiation Measurement (ARM) Program (United States) [data set], available at: https://adc.arm.gov/ discovery/\#/results/datastream::sgpco2flx25mC1.b1 (last access: 7 March 2020), 2015

Bodini, N. and Optis, M.: The importance of round-robin validation when assessing machine-learning-based vertical extrapolation of wind speeds, Wind Energ. Sci., 5, 489-501, https://doi.org/10.5194/wes-5-489-2020, 2020.

Bogenschutz, P. A. and Krueger, S. K.: A simplified PDF parameterization of subgrid-scale clouds and turbulence for cloud-resolving models, J. Adv. Model. Earth Syst., 5, 195-211, 2013.

Bonin, T. A., Carroll, B. J., Hardesty, R. M., Brewer, W. A., Hajny, K., Salmon, O. E., and Shepson, P. B.: Doppler lidar observations of the mixing height in Indianapolis using an automated composite fuzzy logic approach, J. Atmos. Ocean. Tech., 35, 473-490, 2018.

Boquet, M., Royer, P., Cariou, J. P., Machta, M., and Valla, M.: Simulation of Doppler lidar measurement range and data availability, J. Atmos. Ocean. Tech., 33, 977-987, 2016.

Breiman, L.: Random Forests, Mach. Learn., 45, 5-32, 2001.

Brooks, I. M.: Finding boundary layer top: Application of a wavelet covariance transform to lidar backscatter profiles, J. Atmos. Ocean. Tech., 20, 1092-1105, 2003.

Brost, R. A. and Wyngaard, J. C.: A model study of the stably stratified planetary boundary layer, J. Atmos. Sci., 35, 1427-1440, 1978.

Cadeddu, M. P., Turner, D. D., and Liljegren, J. C.: A neural network for real-time retrievals of PWV and LWP from Arctic millimeter-wave ground-based observations, IEEE T. Geosci. Remote, 47, 1887-1900, 2009.

Campbell, J. R., Hlavka, D. L., Welton, E. J., Flynn, C. J., Turner, D. D., Spinhirne, J. D., Scott III, V. S., and Hwang, I. H.: Fulltime, eye-safe cloud and aerosol lidar observation at atmospheric radiation measurement program sites: Instruments and data processing, J. Atmos. Ocean. Tech., 19, 431-442, 2002. 
Champagne, F. H., Friehe, C. A., LaRue, J. C., and Wynagaard, J. C.: Flux measurements, flux estimation techniques, and finescale turbulence measurements in the unstable surface layer over land, J. Atmos. Sci., 34, 515-530, 1977.

Clough, S. A., Shephard, M. W., Mlawer, E., Delamere, J. S., Iacono, M., Cady-Pereira, K., Boukabara, S., and Brown, P. D.: Atmospheric radiative transfer modeling: A summary of the AER codes, J. Quant. Spectrosc. Ra., 91, 233-244, 2005.

Cohn, S. A. and Angevine, W. M.: Boundary layer height and entrainment zone thickness measured by lidars and wind-profiling radars, J. Appl. Meteorol., 39, 1233-1247, 2000.

Cook, D., Kyrouac, J., Keeler, E., Sullivan, R., and Ermold, B.: Soil Temperature and Moisture Profiles at Southern Great Plains central facility, DOE Office of Science Atmospheric Radiation Measurement (ARM) Program (United States) [data set], https://doi.org/10.5439/1256098, 2016.

Cook, D. R.: Eddy correlation flux measurement system (ECOR) instrument handbook (No. DOE/SC-ARM-TR-052), DOE Office of Science Atmospheric Radiation Measurement (ARM) Program (United States), Lemont, Illinois, USA, 2018a.

Cook, D. R.: Soil Temperature and Moisture Profile (STAMP) System Instrument Handbook (No. DOE/SC-ARM-TR-186), DOE Office of Science Atmospheric Radiation Measurement (ARM) Program (United States), Lemont, Illinois, USA, $2018 \mathrm{~b}$.

Cook, D. R. and Sullivan, R. C.: Surface Energy Balance System (SEBS) Instrument Handbook (No. DOE/SC-ARM-TR-092), DOE Office of Science Atmospheric Radiation Measurement (ARM) Program (United States), Lemont, Illinois, USA, 2019.

Deardorff, J. W.: Stratocumulus-capped mixed layers derived from a 3-dimensional model, Bound.-Lay. Meteorol., 18, 495-527, 1980.

Delle Monache, L., Perry, K. D., Cederwall, R. T., and Ogren, J. A.: In situ aerosol profiles over the Southern Great Plains cloud and radiation test bed site: 2. Effects of mixing height on aerosol properties, J. Geophys. Res.-Atmos., 109, D06209, https://doi.org/10.1029/2003JD004024, 2004.

Emeis, S., Schäfer, K., and Münkel, C.: Surface-based remote sensing of the mixing-layer height - a review, Meteorol. Z., 17, 621630, 2008

Fast, J. D., Berg, L. K., Alexander, L., Bell, D., D’Ambro, E., Hubbe, J., Kuang, C., Liu, J., Long, C., Matthews, A., and Mei, F.: Overview of the HI-SCALE field campaign: A new perspective on shallow convective clouds, B. Am. Meteorol. Soc., 100, 821-840, 2019.

Fernando, H. J. S. and Weil, J. C.: Whither the stable boundary layer? A shift in the research agenda, B. Am. Meteorol. Soc., 91, 1475-1484, 2010.

Gagne II, D. J., Haupt, S. E., Nychka, D. W., and Thompson, G.: Interpretable deep learning for spatial analysis of severe hailstorms, Mon. Weather Rev., 147, 2827-2845, 2019.

Golaz, J. C., Larson, V. E., and Cotton, W. R.: A PDF-based model for boundary layer clouds. Part I: Method and model description, J. Atmos. Sci., 59, 3540-3551, 2002.

Golaz, J. C., Caldwell, P. M., Van Roekel, L. P., Petersen, M. R., Tang, Q., Wolfe, J. D., and Zhu, Q.: The DOE E3SM coupled model version 1: Overview and evaluation at standard resolution, J. Adv. Model. Earth Syst., 11, 2089-2129, 2019.

Grant, A. L. M.: An observational study of the evening transition boundary-layer, Q. J. Roy. Meteor. Soc., 123, 657-677, 1997.
Gustafson, W. I., Vogelmann, A. M., Cheng, X., Endo, S., Krishna, B., Li, Z., Toto, T., and Xiao, H.: Recommendations for Implementation of the LASSO Workflow, DOE Atmospheric Radiation Measurement Climate Research Facility, Richland, Washington, USA, DOE/SC-ARM-17-031, 2017.

Gustafson Jr., W. I., Vogelmann, A. M., Li, Z., Cheng, X., Dumas, K. K., Endo, S., Johnson, K. L., Krishna, B., Fairless, T., and Xiao, H.: The Large-Eddy Simulation (LES) Atmospheric Radiation Measurement (ARM) Symbiotic Simulation and Observation (LASSO) Activity for Continental Shallow Convection, B. Am. Meteorol. Soc., 101, E462-E479, 2020.

Hastie, T., Tibshirani, R., and Friedman, J. (Eds.): The elements of statistical learning: data mining, inference, and prediction, Springer Science \& Business Media, Stanford, California, USA, 2009.

Heffter, J. L.: Transport layer depth calculations, B. Am. Meteorol. Soc., 61, 97-97, 1980.

Hennemuth, B. and Lammert, A.: Determination of the atmospheric boundary layer height from radiosonde and lidar backscatter, Bound.-Lay. Meteorol., 120, 181-200, 2006.

Iacono, M. J., Delamere, J. S., Mlawer, E. J., Shephard, M. W., Clough, S. A., and Collins, W. D.: Radiative forcing by long-lived greenhouse gases: Calculations with the AER radiative transfer models, J. Geophys. Res., 113, D13103, https://doi.org/10.1029/2008JD009944, 2008.

Karlsson, J., Svensson, G., Cardoso, S., Teixeira, J., and Paradise, S.: Subtropical cloud-regime transitions: Boundary layer depth and cloud-top height evolution in models and observations, J. Appl. Meteorol. Clim., 49, 1845-1858, 2010.

Knuteson, R. O., Revercomb, H. E., Best, F. A., Ciganovich, N. C., Dedecker, R. G., Dirkx, T. P., Ellington, S. C., Feltz, W. F., Garcia, R. K., Howell, H. B., and Smith, W. L.: Atmospheric emitted radiance interferometer. Part II: Instrument performance, J. Atmos. Ocean. Tech., 21, 1777-1789, 2004.

Krishnamurthy, R., Choukulkar, A., Calhoun, R., Fine, J., Oliver, A., and Barr, K. S.: Coherent Doppler lidar for wind farm characterization, Wind Energy, 16, 189-206, 2013.

Krishnamurthy, R., Newsom, R. K., Chand, D., and Shaw, W. J., Boundary Layer Climatology at ARM Southern Great Plains, PNNL-30832, Pacific Northwest National Laboratory, Richland, WA, USA, 2020.

Kyrouac, J., Ritsche, M., Hickmon, N., and Holdridge, D.: Surface Meteorological Instrumentation at Southern Great Plains central facility, DOE Office of Science Atmospheric Radiation Measurement (ARM) Program (United States) [data set], https://doi.org/10.5439/1025220, 1993.

Lareau, N. P.: Subcloud and Cloud-Base Latent Heat Fluxes during Shallow Cumulus Convection, J. Atmos. Sci., 77, 1081-1100, 2020.

Lareau, N. P., Zhang, Y., and Klein, S. A.: Observed boundary layer controls on shallow cumulus at the ARM Southern Great Plains site, J. Atmos. Sci., 75, 2235-2255, 2018.

Larson, V. E.: CLUBB-SILHS: A parameterization of subgrid variability in the atmosphere, arXiv [preprint], arXiv:1711.03675v3, 10 November 2017.

Larson, V. E. and Golaz, J. C.: Using probability density functions to derive consistent closure relationships among higherorder moments, Mon. Weather Rev., 133, 1023-1042, 2005. 
LeMone, M. A., Angevine, W. M., Bretherton, C. S., Chen, F., Dudhia, J., Fedorovich, E., Katsaros, K. B., Lenschow, D. H., Mahrt, L., Patton, E. G., and Sun, J.: 100 years of progress in boundary layer meteorology, Meteor. Mon., 59, 9.1-9.85, 2018.

Lenschow, D. H., Wyngaard, J. C., and Pennell, W.T.: Mean-field and second-moment budgets in a baroclinic, convective boundary layer, J. Atmos. Sci., 37, 1313-1326, 1980.

Lenschow, D. H., Wulfmeyer, V., and Senff, C.: Measuring secondthrough fourth-order moments in noisy data, J. Atmos. Ocean. Tech., 17, 1330-1347, 2000.

Lenschow, D. H., Lothon, M., Mayor, S. D., Sullivan, P. P., and Canut, G.: A comparison of higher-order vertical velocity moments in the convective boundary layer from lidar with in situ measurements and large-eddy simulation, Bound.-Lay. Meteorol., 143, 107-123, 2012.

Liu, S. and Liang, X. Z.: Observed diurnal cycle climatology of planetary boundary layer height, J. Climate, 23, 5790-5809, 2010.

Markowski, P. and Richardson, Y.: Organization of isolated convection, Mesoscale meteorology in midlatitudes, Wiley-Blackwell, Pennsylvania, USA, 201-244, 2010.

Marsik, F. J., Fischer, K. W., McDonald, T. D., and Samson, P. J.: Comparison of methods for estimating mixing height used during the 1992 Atlanta Field Intensive, J. Appl. Meteorol. Clim., 34, 1802-1814, 1995.

Mather, J., Goss, H., and Jundt, R.: 2017 Annual Report, edited by: Jundt, R., ARM Climate Research Facility, Richland, Washington, USA, DOE/SC-ARM-17-038, 2018.

Mather, J. H. and Voyles, J. W.: The ARM Climate Research Facility: A review of structure and capabilities, B. Am. Meteorol. Soc., 94, 377-392, 2013.

McCord, R. and Voyles, J. W.: The ARM data system and archive. The Atmospheric Radiation Measurement Program: The First 20 Years, Meteor. Monograph. Amer. Meteor. Soc., 57, 11.1-11.15, 2016.

McGovern, A., Elmore, K. L., Gagne, D. J., Haupt, S. E., Karstens, C. D., Lagerquist, R., Smith, T., and Williams, J. K.: Using artificial intelligence to improve real-time decision-making for highimpact weather, B. Am. Meteorol. Soc., 98, 2073-2090, 2017.

McNicholas, C. and Turner, D. D.: Characterizing the convective boundary layer turbulence with a High Spectral Resolution Lidar, J. Geophys. Res.-Atmos., 119, 12910-12927, 2014.

Mlawer, E. J., Taubman, S. J., Brown, P. D., Iacono, M. J., and Clough, S. A.: Radiative transfer for inhomogeneous atmospheres: RRTM, a validated correlated-k model for the longwave, J. Geophys. Res., 102, 16663-16682, 1997.

Newsom, R. K. and Krishnamurthy, R.: Doppler lidar observations of radial velocity, backscatter and signal-to-noise ratio at Southern Great Plains central facility, handbook, No. DOE/SCARM/TR-101, DOE Office of Science Atmospheric Radiation Measurement (ARM) Program (United States) [data set], https://doi.org/10.5439/1025185, 2020.

Newsom, R. K., Sivaraman, C., Shippert, T. R., and Riihimaki, L. D.: Doppler Lidar WIND Value-Added Product (No. DOE/SCARM/TR-148), DOE Office of Science Atmospheric Radiation Measurement (ARM) Program (United States), Richland, Washington, USA, 2019a.

Newsom, R. K., Sivaraman, C., Shippert, T. R., and Riihimaki, L. D.: Doppler Lidar Vertical Velocity Statistics Value-Added
Product (No. DOE/SC-ARM/TR-149), DOE Office of Science Atmospheric Radiation Measurement (ARM) Program (United States), Richland, Washington, USA, 2019b.

Pearson, G., Davies, F., and Collier, C.: An analysis of the performance of the UFAM pulsed Doppler lidar for observing the boundary layer, J. Atmos. Ocean. Tech., 26, 240-250, 2009.

Quan, J., Gao, Y., Zhang, Q., Tie, X., Cao, J., Han, S., Meng, J., Chen, P., and Zhao, D.: Evolution of planetary boundary layer under different weather conditions, and its impact on aerosol concentrations, Particuology, 11, 34-40, 2013.

Rasch, P. J., Xie, S., Ma, P.L., Lin, W., Wang, H., Tang, Q., Burrows, S. M., Caldwell, P., Zhang, K., Easter, R. C., and CameronSmith, P.: An overview of the atmospheric component of the Energy Exascale Earth System Model, J. Adv. Model. Earth Syst., 11, 2377-2411, 2019.

Reif, D. W. and Bluestein, H. B.: A 20-year climatology of nocturnal convection initiation over the central and southern Great Plains during the warm season, Mon. Weather Rev., 145, 16151639, 2017.

Riihimaki, L., Sivaraman, C., and Zhang, D.: Planetary Boundary Layer Height observations from Radiosondes at Southern Great Plains central facility, DOE Office of Science Atmospheric Radiation Measurement (ARM) Program (United States) [data set], https://doi.org/10.5439/1150253, 2001.

Ritsche, M. T. and Prell, J.: ARM Surface Meteorology Systems (MET) Handbook, DOE/SC-ARM/TR-086, DOE Office of Science Atmospheric Radiation Measurement (ARM) Program (United States), Lemont, Illinois, USA, 2011.

Santanello Jr., J. A., Friedl, M. A., and Kustas, W. P.: An empirical investigation of convective planetary boundary layer evolution and its relationship with the land surface, J. Appl. Meteorol., 44, 917-932, 2005.

Santanello Jr., J. A., Friedl, M. A., and Ek, M. B.: Convective planetary boundary layer interactions with the land surface at diurnal time scales: Diagnostics and feedbacks, J. Hydrometeorol., 8, 1082-1097, 2007.

Sawyer, V. and Li, Z.: Detection, variations and intercomparison of the planetary boundary layer depth from radiosonde, lidar and infrared spectrometer, Atmos. Environ., 79, 518-528, 2013.

Schween, J. H., Hirsikko, A., Löhnert, U., and Crewell, S.: Mixinglayer height retrieval with ceilometer and Doppler lidar: from case studies to long-term assessment, Atmos. Meas. Tech., 7, 3685-3704, https://doi.org/10.5194/amt-7-3685-2014, 2014.

Seibert, P., Beyrich, F., Gryning, S. E., Joffre, S., Rasmussen, A., and Tercier, P.: Review and intercomparison of operational methods for the determination of the mixing height, Atmos. Environ., 34, 1001-1027, 2000.

Sisterson, D. L., Peppler, R. A., Cress, T. S., Lamb, P. J., and Turner, D. D.: The ARM Southern Great Plains (SGP) site. The Atmospheric Radiation Measurement Program: The First 20 Years, Meteor. Monograph. Amer. Meteor. Soc., 57, 6.1-6.14, 2016.

Shukla, K. K., Phanikumar, D. V., Newsom, R. K., Kumar, K. N., Ratnam, M. V., Naja, M., and Singh, N.: Estimation of the mixing layer height over a high altitude site in Central Himalayan region by using Doppler lidar, J. Atmos. Sol.-Terr. Phy., 109, 48-53, 2014.

Sivaraman, C., McFarlane, S., Chapman, E., Jensen, M., Toto, T., Liu, S., and Fischer, M.: Planetary Boundary Layer Height Value Added Product (VAP): Radiosonde Retrievals, Department of 
Energy Office of Science Atmospheric Radiation Measurement (ARM) Program (United States), Richland, Washington, USA, 2013.

Skamarock, W. C., Klemp, J. B., Dudhia, J., Gill, D. O., Barker, D. M., Duda, M. G., Wang, W., and Powers, J. G.: A description of the advanced research WRF version 3. NCAR Technical Note, NCAR/TN-475+STR, National Center for Atmospheric Research, Boulder, Colorado, USA, 113 pp., 2008.

Solheim, F., Godwin, J. R., Westwater, E. R., Han, Y., Keihm, S. J., Marsh, K., and Ware, R.: Radiometric profiling of temperature, water vapor, and cloud liquid water using various inversion methods, Radio Sci., 33, 393-404, 1998.

Sullivan, R., Cook, D., and Keeler, E.: Surface Energy Balance System at Southern Great Plains central facility, DOE Office of Science Atmospheric Radiation Measurement (ARM) Program (United States) [data set], https://doi.org/10.5439/1025274, 2010.

Summa, D., Di Girolamo, P., Stelitano, D., and Cacciani, M.: Characterization of the planetary boundary layer height and structure by Raman lidar: comparison of different approaches, Atmos. Meas. Tech., 6, 3515-3525, https://doi.org/10.5194/amt-6-35152013, 2013.

Tang, Q., Xie, S., Zhang, Y., Phillips, T. J., Santanello, J. A., Cook, D. R., Riihimaki, L. D., and Gaustad, K. L.: Heterogeneity in warm-season land-atmosphere coupling over the US Southern Great Plains, J. Geophys. Res.-Atmos., 123, 7867-7882, 2018.

Tang, S., Xie, S., Zhang, Y., and Cook, D. R.: The QCECOR ValueAdded Product: Quality-Controlled Eddy Correlation Flux Measurements (No. DOE/SC-ARM-TR-223), DOE Office of Science Atmospheric Radiation Measurement (ARM) Program (United States), Livermore, California, USA, 2019.

Teixeira, J. and Cheinet, S., A simple mixing length formulation for the eddy-diffusivity parameterization of dry convection, Bound.Lay. Meteorol., 110, 435-453, 2004.

Thompson, G., Rasmussen, R. M., and Manning, K.: Explicit forecasts of winter precipitation using an improved bulk microphysics scheme. Part I: Description and sensitivity analysis, Mon. Weather Rev., 132, 519-542, 2004.

Thompson, G., Field, P. R., Rasmussen, R. M., and Hall, W. D.: Explicit forecasts of winter precipitation using an improved bulk microphysics scheme. Part II: Implementation of a new snow parameterization, Mon. Weather Rev., 136, 5095-5115, 2008.

Tibshirani, R.: Regression shrinkage and selection via the lasso, J. Roy. Stat. Soc. B, 58, 267-288, 1996.
Träumner, K., Kottmeier, C., Corsmeier, U., and Wieser, A.: Convective boundary-layer entrainment: Short review and progress using Doppler lidar, Bound.-Lay. Meteorol., 141, 369-391, 2011.

Tucker, S. C., Senff, C. J., Weickmann, A. M., Brewer, W. A., Banta, R. M., Sandberg, S. P., Law, D. C., and Hardesty, R. M.: Doppler lidar estimation of mixing height using turbulence, shear, and aerosol profiles, J. Atmos. Ocean. Tech., 26, 673-688, 2009.

Turner, D. D., Wulfmeyer, V., Berg, L. K., and Schween, J. H.: Water vapor turbulence profiles in stationary continental convective mixed layers, J. Geophys. Res.-Atmos., 119, 11-151, 2014.

Vakkari, V., O'Connor, E. J., Nisantzi, A., Mamouri, R. E., and Hadjimitsis, D. G.: Low-level mixing height detection in coastal locations with a scanning Doppler lidar, Atmos. Meas. Tech., 8, 1875-1885, https://doi.org/10.5194/amt-8-1875-2015, 2015.

Vassallo, D., Krishnamurthy, R., and Fernando, H. J. S.: Decreasing wind speed extrapolation error via domain-specific feature extraction and selection, Wind Energ. Sci., 5, 959-975, https://doi.org/10.5194/wes-5-959-2020, 2020.

Vassallo, D., Krishnamurthy, R., and Fernando, H. J. S.: Utilizing physics-based input features within a machine learning model to predict wind speed forecasting error, Wind Energ. Sci., 6, 295309, https://doi.org/10.5194/wes-6-295-2021, 2021.

Weckworth, T. M., Spuler, S., and Turner, D. D.: Micropulse Differential Absorption Lidar (MPD) Network Demonstration Field Campaign Report (No. DOE/SC-ARM-20-002), ARM Data Center, Oak Ridge National Laboratory (ORNL), Oak Ridge, TN, USA, 2020.

Wharton, S. and Lundquist, J. K.: Assessing atmospheric stability and its impacts on rotor-disk wind characteristics at an onshore wind farm, Wind Energy, 15, 525-546, 2012.

Wood, R. and Bretherton, C. S.: Boundary layer depth, entrainment, and decoupling in the cloud-capped subtropical and tropical marine boundary layer, J. Climate, 17, 3576-3588, 2004.

Yoo, W., Mayberry, R., Bae, S., Singh, K., He, Q. P., and Lillard Jr., J. W.: A study of effects of multicollinearity in the multivariable analysis, International journal of applied science and technology, 4, 9-19, 2014.

Zhang, Y., Seidel, D. J., and Zhang, S.: Trends in planetary boundary layer height over Europe, J. Climate, 26, 10071-10076, 2013.

Zilitinkevich, S. and Baklanov, A.: Calculation of the height of the stable boundary layer in practical applications, Bound.-Lay. Meteorol., 105, 389-409, 2002.

Zilitinkevich, S. S.: On the determination of the height of the Ekman boundary layer, Bound.-Lay. Meteorol., 3, 141-145, 1972. 